\title{
Inducible intracellular membranes: molecular aspects and emerging applications
}

\author{
Jorge Royes ${ }^{1,2,3^{*}}$, Valérie Biou ${ }^{1,2}$, Nathalie Dautin ${ }^{1,2}$, Christophe Tribet ${ }^{3}$ and Bruno Miroux ${ }^{1,2^{*}}$
}

\begin{abstract}
Membrane remodeling and phospholipid biosynthesis are normally tightly regulated to maintain the shape and function of cells. Indeed, different physiological mechanisms ensure a precise coordination between de novo phospholipid biosynthesis and modulation of membrane morphology. Interestingly, the overproduction of certain membrane proteins hijack these regulation networks, leading to the formation of impressive intracellular membrane structures in both prokaryotic and eukaryotic cells. The proteins triggering an abnormal accumulation of membrane structures inside the cells (or membrane proliferation) share two major common features: (1) they promote the formation of highly curved membrane domains and (2) they lead to an enrichment in anionic, cone-shaped phospholipids (cardiolipin or phosphatidic acid) in the newly formed membranes. Taking into account the available examples of membrane proliferation upon protein overproduction, together with the latest biochemical, biophysical and structural data, we explore the relationship between protein synthesis and membrane biogenesis. We propose a mechanism for the formation of these non-physiological intracellular membranes that shares similarities with natural inner membrane structures found in a-proteobacteria, mitochondria and some viruses-infected cells, pointing towards a conserved feature through evolution. We hope that the information discussed in this review will give a better grasp of the biophysical mechanisms behind physiological and induced intracellular membrane proliferation, and inspire new applications, either for academia (high-yield membrane protein production and nanovesicle production) or industry (biofuel production and vaccine preparation).
\end{abstract}

Keywords: Membrane remodeling, Membrane biosynthesis, Membrane curvature, Phospholipids, Inner membrane, Lipid biosynthesis

\section{Background}

Biological membranes are complex, two-dimensional structured assemblies of phospholipids containing a high density of proteins and carbohydrates. The possibility of controlling the production and organization of biological membranes is still an open question and it has several implications for biotechnology. For example, the increased phospholipid amount due to membrane expansion is useful in the field of biofuel production by

\footnotetext{
*Correspondence: jordi.royesmir@ibpc.fr; bruno.miroux@ibpc.fr ${ }^{1}$ Laboratoire de Biologie Physico-Chimique des Protéines Membranaires, Université de Paris, LBPC-PM, CNRS, UMR7099, 75005 Paris, France

${ }^{2}$ Institut de Biologie Physico-Chimique, Fondation Edmond de Rothschild pour le Développement de la Recherche Scientifique, 75005 Paris, France Full list of author information is available at the end of the article
}

fermentation. Modification of metabolic pathways aiming at diverting carbon fluxes towards the desired target compound has been tried and is far from being straightforward [1,2]. In this context, the overexpression of a protein triggering membrane proliferation represents a simple, alternative strategy to redirect lipid metabolism and enhance biofuel production yield. In the same line, production of the P9 and P12 phage $\phi 6$ viral proteins have been proposed to increase the yield of useful hydrophobic active principles [3].

For structural biologists, membrane protein production still represents a major technological challenge [4]. Despite the emergence of eukaryotic expression systems, prokaryotic expression systems are the most popular vehicle for membrane protein production [5].

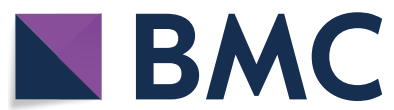

(c) The Author(s) 2020. This article is licensed under a Creative Commons Attribution 4.0 International License, which permits use, sharing, adaptation, distribution and reproduction in any medium or format, as long as you give appropriate credit to the original author(s) and the source, provide a link to the Creative Commons licence, and indicate if changes were made. The images or other third party material in this article are included in the article's Creative Commons licence, unless indicated otherwise in a credit line to the material. If material is not included in the article's Creative Commons licence and your intended use is not permitted by statutory regulation or exceeds the permitted use, you will need to obtain permission directly from the copyright holder. To view a copy of this licence, visit http://creativeco mmons.org/licenses/by/4.0/. The Creative Commons Public Domain Dedication waiver (http://creativecommons.org/publicdomain/ zero/1.0/) applies to the data made available in this article, unless otherwise stated in a credit line to the data. 
Historically, genetically modified strains have been developed to enhance membrane protein production [6-8]. Recently, a novel strategy has arisen for membrane protein production both in prokaryotes and eukaryotes, relying on tuning the cell membrane phospholipid composition to accommodate higher amounts of recombinant membrane proteins $[9,10]$. Alternatively, some of the proteins triggering internal membrane proliferation have been proposed as a fusion partner to membrane proteins to trigger membrane expansion and increase the yield of membrane protein production [11]. The next generation of membrane protein production platforms may combine those three strategies: genetic regulation of protein expression, modulation of phospholipid composition, and membrane expansion triggered by protein overproduction.

Membrane production platforms could also find applications in nanotechnology and nanomedicine. Almost all cell types secrete nano- and micro-sized vesicles used for intercellular communication [12, 13]. Granting control over the production and composition of those vesicles hold great promises in nanotechnology and nanomedicine $[14,15]$. In this regard, the protein-induced intracellular membrane proliferation has been suggested as a new route to increase production yield of microvesicles for antiviral or tumoral treatments, or as contrast agents in bioimaging [16-19]. Membrane proliferation upon overproduction of the $b$ subunit of $F_{o} F_{1}$-ATP synthase has been recently used to prepare proteoliposomes [20]. This method represents an attractive alternative to in vitro proteoliposomes reconstitution, alleviating several steps of protein extraction, purification and reconstitution in liposomes. In the same line, the preparation of bacteria-derived lipid vesicles presenting antigenic proteins from pathogens on their surface have been used for vaccine preparation $[21,22]$. The production of chimera proteins containing a membrane-proliferation domain and an adequate antigen could dramatically improve vaccine safety and mass production.

Here, we will critically review and rationalize the available knowledge gained from studying membrane remodeling in physiological context to find the basic physico-chemical principles governing membrane production that can be applied to inducible non-physiological membrane rearrangements. We hope that the mechanistic principles proposed in this review can help to harness this phenomenon in the design of new biotechnological applications.

\section{Influence of membrane curvature in membrane remodeling}

From a biological standpoint, membranes are lipidic films that define the boundaries of cells and organelles.
They constitute permeability barriers and major sites of exchange between the interior and exterior of these cells and compartments. Thus, they are essential for compartmentalizing the biochemical reactions that sustain life. Membranes are composed of lipids arranged as bilayers, together with proteins that can be either inserted in the lipid layer or peripherally associated to it. Membrane organization, as well as lipid and protein constituents, vary between organisms (eukaryotic cells, bacteria, virus), but also among species of certain organism. Furthermore, membrane composition changes in response to various signals or environmental conditions resulting in three-dimensional rearrangements, or membrane remodeling events. These spatial rearrangements occur in all life forms; however, the exact mechanisms underlying these events have mainly been deciphered in eukaryotic cells and are starting to be understood in prokaryotes.

Eukaryotic cells possess various essential intracellular organelles (endoplasmic reticulum (ER), Golgi apparatus, endosome, mitochondria...), which differ in morphology, function and structure but are all bounded by bilayers with increased curvature compared to the cell membrane. In addition, multiple membrane remodeling events have to be coordinated to carry out physiological processes such as vesicular trafficking, endocytosis or exocytosis. These processes, which have been studied for decades, depend on a large array of proteins, either cytoskeletal (actin, tubulin) or directly implicated in membrane curvature and remodeling, such as clathrin, dynamins or BAR (Bin-Amphiphysin-Rvs) or ENTH (Epsin NH2-Terminal Homology) domain-containing proteins. For a long time, these complex membrane remodeling processes were thought to be an exclusive features of eukaryotic cells. Recently, it has been demonstrated that prokaryotic cells also undergo multiple membrane remodeling processes which are similarly controlled by specific proteins, analogous to the ones found in eukaryotic cells [23]. Regardless of the different protein complexes involved for each organism, from a biophysical perspective, four basic molecular mechanisms have been described to remodel biological membrane, modifying their curvature (Fig. 1) [24]:

a. Pushing or pulling the membrane using molecular motors.

b. Bending along a rigid supramolecular protein scaffold.

c. Asymmetric interaction of proteins with only one leaflet of the lipid bilayer.

d. Insertion of wedge-shaped proteins into the membrane. 

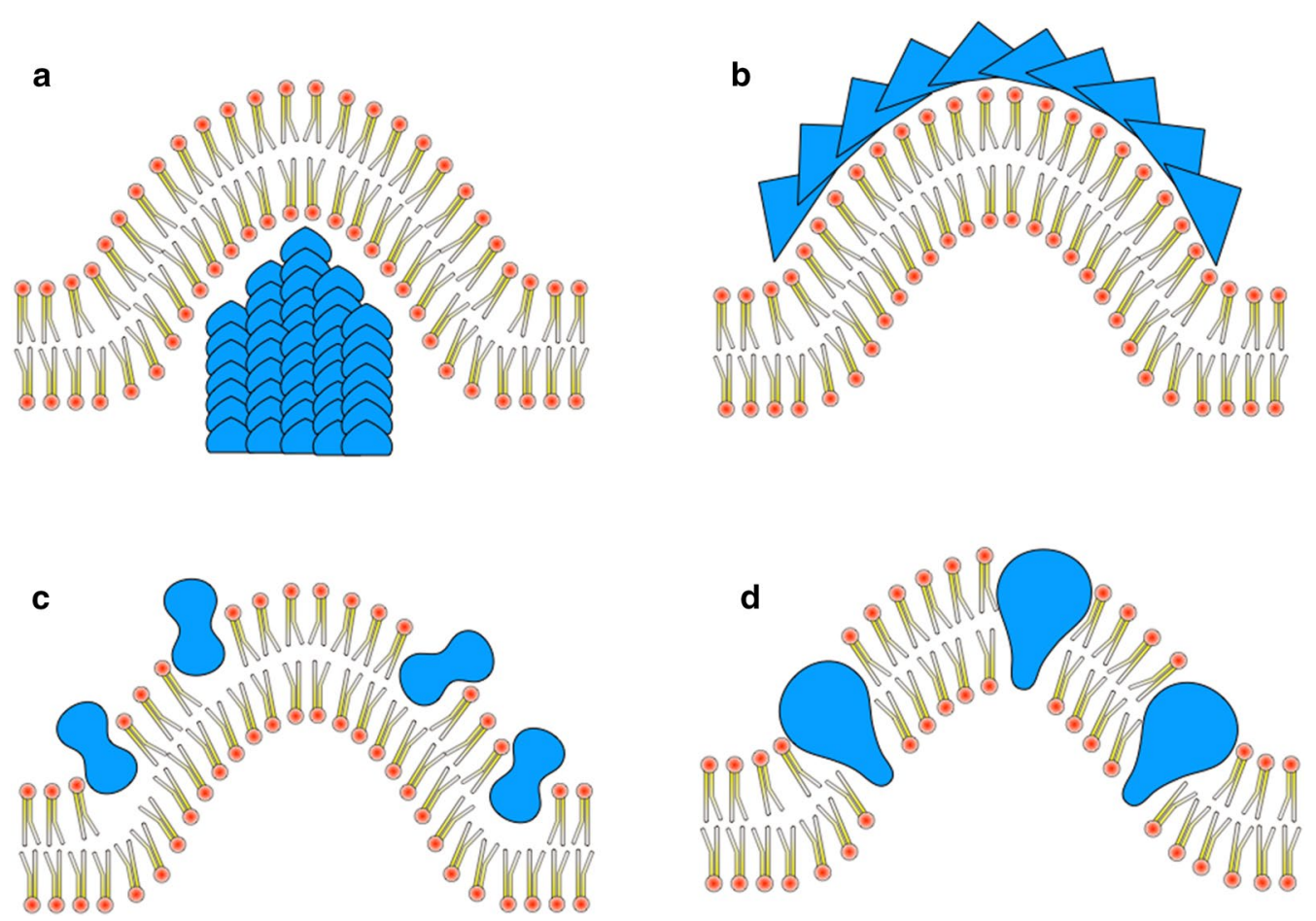

Fig. 1 Different mechanisms of membrane deformation a push force by molecular motors, b protein supramolecular scaffolding, $\mathbf{c}$ asymmetric interaction with one leaflet of the membrane and $\mathbf{d}$ insertion of wedged-shaped proteins.

Those biophysical mechanisms are ubiquitous and involved in multiple physiological processes.

\section{Examples of proteins modifying membrane-curvature}

Proteins with ENTH domains in eukaryotes insert a wedged-shaped N-terminal amphipathic helix into the membrane, leading to curvature and deformation of the membrane (Fig. 1a). ENTH-containing proteins are also involved in clathrin mediated budding by regulating and promoting the scaffolding of clathrin on membrane (Fig. 1b). However, for the moment proteins with ENTH domains have only been observed in eukaryotes.

Another example are BAR domains, which form banana-shaped dimers that can bind membrane with curvature but also induce and stabilize membrane curvature via helical oligomerization and scaffolding [25]. BAR domain interaction also leads to phosphoinositides lipid clustering and formation of stable microdomains [26]. BAR-domain proteins functions are multiple: they regulate actin polymerization by interacting and recruiting actin assembly factors at the membrane, they cooperate with dynamin and clathrin to mediate membrane fission during endocytosis and are involved in the formation of filopodia and lamellipodia [25]. Only 2 BAR-containing proteins have been described so far in bacteria, BdpA from Shewanella oneidensis is involved in the biogenesis of outer membrane extensions and trigger the formation of such extensions when expressed in a heterologous host $(E$. coli) [27]. MamY is a BAR-domain protein implicated in magnetosome formation [28].

The Dynamin superfamily of proteins includes some of the best studied membrane remodeling proteins; in particular, those involved in endocytosis, organelle formation and maintenance, and cytokinesis in eukaryotic cells. Dynamins are molecular motors that modify membrane curvature (Fig. 1a). They are characterized by a GTPase domain, an elongated alpha-helical bundle that drives self-assembly, and the capacity to interact with lipids and membrane. They promote membrane tubules formation by self-assembling as an helical scaffold. GTP hydrolysis induces a conformational change in this scaffold that leads to further membrane constriction and possibly membrane fission or fusion [29]. In bacteria, multiple dynamin-like proteins (BDLP: Bacterial Dynamin Like Proteins) capable of modifying membrane curvature have been identified but their physiological roles are not entirely known. Some have been localized to the division septum, suggesting a role in cell division [30]. The two BDLP DynA and DynB for instance, are necessary for the cytokinesis event preceding sporulation in Streptomyces venezuelae [31]. Also, Bacillus subtilis DynA, a BDLP 
localized at the septa, mediates immunity against phage infection and membrane stress and it is also thought to be involved in membrane remodeling, since this protein is able to perform lipid mixing and membrane fusion in vitro, in a GTP-independent process [32-34]. A similar function in membrane repair and maintenance has been assigned to the M. tuberculosis BDLP IniA, which is capable to modify the membrane curvature of cardiolipin (CL)-containing liposomes and induce GTP-dependent membrane fission in vitro [35]. Finally, Escherichia coli LeoA, B and C are periplasmic BDLP implicated in outer membrane vesicles formation, although a direct interaction with lipids or a capacity to remodel membranes has not been demonstrated [36].

\section{Bacterial cell division requires a coordination of membrane curvature modulating events}

Another interesting illustration of physiological event requiring major membrane remodeling and membrane curvature modifications is bacterial cell division. Bacterial cells can be bounded by one or two membranes. Monodermic bacteria only possess one membrane, the cytoplasmic membrane, which is usually surrounded by a thick layer of peptidoglycan. In contrast, didermic bacteria have two membranes: the inner membrane (which corresponds to the cytoplasmic membrane of monodermic bacteria) and the outer membrane, separated by the so-called periplasm, which contains a peptidoglycan layer. During division, all those membrane layers must be remodeled to yield two independent bacteria. Membrane invagination required for bacterial cell division appears to be driven by forced membrane bending. Septum formation first requires the spatially regulated, hierarchical assembly of a multiprotein complex called the divisome. The correct positioning of the divisome at midcell is ensured by the Min and the nucleoid occlusion (NOc) systems, which are themselves dependent on and regulated by membrane lipids, especially anionic lipids microdomains found at the poles and septum [37, 38]. Amongst the more than 20 proteins that constitute the divisome, the tubulin-like GTPase FtsZ plays a central role in membrane invagination by oligomerizing into a dynamic, cytoplasmic Z-ring attached to the membrane via ZipA and FtsA. The complex further serves as a docking site for other divisome components. The role of FtsZ in membrane invagination has been debated. Its ability to display intrinsic curvature in its polymeric state and deform various artificial membranes in vitro [39], led to a model in which the cytoplasmic membrane is pulled inward by Z-ring constriction during cytokinesis. However, it has also been suggested that FtsZ only serves as a scaffold onto which the peptidoglycan remodeling machinery assembles. In the latter case, it is the growth of the septal cell wall that pushes the membrane toward the center of the cell [40]. In addition, the actin-like ATPase FtsA, which interacts with phospholipids via its C-terminus and bridges FtsZ to the membrane, was shown to induce membrane rearrangement in vitro and vesicle formation upon overexpression in E. coli [41]. It was thus proposed to facilitate membrane invagination by deforming the membrane at the septum site [41, 42]. Whatever its exact mechanism of formation, the membrane curvature generated upon membrane invagination in turn participates in the recruitment of negative curvature-specific proteins such as DivIVA, which further binds other players of cell division and localizes them at the septum site. The final steps of bacterial cell division (fusion and fission of the membrane(s) leading to the separation of the two daughter cells) are not characterized yet and it is still unclear whether specific fusion/fission proteins complexes are necessary or if membrane fission occurs spontaneously as a consequence of membrane curvature and/or protein crowding $[43,44]$. A role for FtsA in this process has been proposed based on the occasional scission observed when FtsA was added to FtsZ-liposome in vitro [45]. However, this is inconsistent with the fact that FtsA, FtsZ and ZipA leave the septum before cell separation [40].

\section{Orchestrated membrane curvature changes during sporulation}

Sporulation is another event occurring in bacteria that involves extensive membrane remodeling. Under unfavorable conditions, the vegetative cells of some species of Gram-positive bacteria, such as Bacillus or Clostridium, produce resistant and metabolically dormant structures called spores. Sporulation starts with an asymmetrical cell division which generates a small cell (forespore) connected to the larger mother cell by two membranes separated by a thin peptidoglycan layer. This step requires the same divisome complex described for vegetative growth. However, whereas septum formation during vegetative growth avoids the nucleoid, during sporulation the septum closes over the chromosome, which is then translocated to the forespore. In B. subtilis, DNA translocation is performed by SpoIIIE, a homologue of E. coli FtsK which localizes at septal midpoint, possibly by its ability to sense regions of increased membrane curvature [46]. SpoIIIE is also required for membrane severing of the cytoplasmic bridge remaining between the mother cell and the forespore after DNA translocation. Although the exact mechanism by which SpoIIIE mediates this event is unknown, it was proposed that the protein forms multimeric channels in the mother cell and forespore membranes. Those channels finally assemble into an intramembrane transchannel whose disassembly triggers membrane separation [47]. After severing of the membranes, the mother 
cell progressively engulfs the forespore, in a phagocytosis-like process, until the forespore is liberated in the cytoplasm of the mother cell, where it will further mature. During engulfment, the mother cell membrane generated at the division site expands and migrates on each side of the forespore until it totally surrounds it and the two leading edges reconnect next to the cell pole. The process of engulfment depends on two complementary ratchet-like mechanisms: the mother cell SpoIIDMP protein complex localized at the leading edge of the engulfing membrane, processively degrades the peptidoglycan synthesized ahead by the forespore and by doing so pulls the membrane forward $[48,49]$. In addition, the forespore protein SpoIIQ interacts with the mother cell SpoIIAH in a zipper-like mechanism, which renders the membrane movement irreversible [50]. Once the two leading edges have meet, they fuse to liberate the forespore in the mother cell cytoplasm. In Bacillus subtilis, this final fusion event depends on SpoIIIE and FisB (Fission protein B) $[47,51]$. FisB is a bitopic membrane protein with a large periplasmic region and a small cytoplasmic domain. Although the exact mechanism by which FisB triggers membrane fusion is still unknown, the protein is able to induce lipid mixing in vitro, in a process depending on the specific interaction between its periplasmic domain and CL. It is thus assumed that FisB, via this interaction, brings the two leading engulfment membranes in close contact before fusion [51]. As expected, sporulation is dependent on a reactivation of de novo membrane lipids synthesis [52]. CL for instance, is strongly enriched in the septum, the forespore and the mother cell engulfment membranes during sporulation [53] and accumulates in the mature spore [54]. Mutant strains producing only trace amounts of $\mathrm{CL}$ show delay in spore formation and produce reduced amounts of spores that are unable to germinate when placed back in favorable conditions [54]. CL enrichment might thus be important for the function of membrane proteins required for sporulation (e.g. FisB) or for their recruitment to specific regions of curvature. Membrane curvature-dependent localization has indeed been shown for B. subtilis SpoVM, which is necessary for spore maturation and localizes at the forespore surface by detecting positively curved membranes and inserting in them by an atypical amphipathic alpha-helix $[55,56]$.

\section{Evolutive origin of intracellular organelles}

Although prokaryotic cells have been historically claimed as organelle-free organisms, several examples of intracellular membrane-restricted compartments have now been identified. For instance, intracellular membrane structures are naturally present in $\alpha$-proteobacteria, an evolutive ancestor of $\gamma$-proteobacteria [57], where they either increase the efficiency of the cell bioenergetic metabolism (anaerobic anoxygenic photosynthesis, nitrifying and/or methanotrophic bacteria, etc.) or provide an evolutive advantage (magnetosome) [58].

\section{Membrane curvature at the origin of mitochondria}

The $\alpha$-proteobacteria intracellular membrane structures have been proposed as potential ancestors of mitochondria inner membrane cristae after the discovery of a common membrane remodeling protein: alphaMic60 and Mic60 in $\alpha$-proteobacteria and mitochondria, respectively [59]. The growth of intracellular membrane structures in both $\alpha$-proteobacteria and mitochondria requires the assembly of the photosynthetic or respiratory protein complexes, which are known to induce strong membrane curvature [60-62]. Mic60 and its analogue alphaMic60 are part of the protein complex that presumably bends the membrane and stabilizes the cristae junctions in mitochondria (or inner membrane invagination points in $\alpha$-proteobacteria). Although modern $\gamma$-proteobacteria lack the gene encoding alphaMic60 [63] and have lost the ability to physiologically produce inner membrane structures, heterologous overproduction of eukaryotic Mic60 restores the capacity of E. coli to produce those inner membrane structures [64]. This result implies that the ancestral mechanism for inner membrane proliferation of $\alpha$-proteobacteria is not completely lost in $\gamma$-proteobacteria, but only dormant, and that it can be restored when certain conditions are met. The presence of $\mathrm{CL}$ in both prokaryotes and mitochondria is another argument often used to defend the endosymbiotic origin of mitochondria [65]. CL fulfills many biological roles in mitochondria and bacteria $[66,67]$. Membrane curvature and CL seem to be linked, as CL depleted mutants show altered internal ultrastructure and function of mitochondria [68]. Furthermore, a recent study illustrates the importance of the formation of highly curved cristae for the correct accumulation of $\mathrm{CL}$ inside the mitochondria [69]. Notably, CL seems to be also related to physiological membrane remodeling processes in bacteria such as sporulation ("Influence of membrane curvature in membrane remodeling" section). Still, how CL, membrane curvature and membrane biosynthesis are exactly related remains a mystery.

\section{Magnetosome formation}

Magnetosomes are 30-120 nm spherical, membranebound compartments that contain iron-rich magnetic particles. They organize as chains along the cell and allow magnetotactic bacteria to sense and orient in the geomagnetic field. They derive from the cytoplasmic membrane to which they may remain attached or not [70]. The mechanism of membrane invagination and vesicle 
formation, which seems to precede biomineralization, has not been completely deciphered but depends on the product of multiple mam (magnetosome membraneassociated) genes. Individual deletions of mam genes have identified four proteins involved in the biogenesis of the membrane of magnetosomes (MamI, MamL, MamQ and MamB) [71, 72]. However, the structure of those proteins has not been resolved and only speculations are available on the mechanism they use to bend the membrane and create the invaginations necessary for magnetosome formation [73, 74]. Besides, the overexpression of each one of those four genes alone is not sufficient to trigger membrane proliferation. More recent studies however suggest that at least some Mam protein might directly induce membrane curvature. In particular, MamY, a BAR domain-containing protein, interacts with liposome and induces liposome tubulation in vitro. Because a mamY mutant of Magnetospirillum magneticum showed altered magnetosome size-distribution, MamY was first proposed to be involved in membrane constriction [28]. However, MamY in vitro tubulation activity is specifically increased upon CL interaction, suggesting that MamY might recruit $\mathrm{CL}$ to the site of magnetosome formation to induce the formation of highly curved membranes [75]. Still, overexpression of MamY in E. coli or M. magneticum did not alter cell membrane morphology, confirming that in vivo, other factors are certainly needed to trigger membrane curvature and vesicle formation [28]. More recently, another study proposed that MamY represents a membrane positive curvature-sensing element and serves as a scaffold to properly align the chain of magnetosome parallel to the axis of the cell [76]. The role of CL in this function was however not tested.

\section{Photosynthetic bacterial organelles}

In some photosynthetic bacteria, intracytoplasmic vesicles called chromatophores contain pigments and lightharvesting proteins used to perform photosynthesis. Chromatophores function depend on the light-harvesting complexes 1 (LH1) and 2 (LH2) together with the reaction center $(\mathrm{RC})$. These complexes, which are also directly implicated in chromatophore formation and shape determination, are thought to induce membrane curvature through a combination of wedging and scaffolding mechanism (Fig. 1). Indeed, the ability of these integral membrane proteins to bend and deform membranes depends on their capacity to oligomerize. The RC-LH1 complex, when monomeric, cannot bend membrane. However, RC-LH1 in complex with the small protein PufX forms dimers with the two monomers bent by a $146^{\circ}$ angle [77-79]. In the absence of LH2, these dimers form tubular chromatophores in vivo [80]. LH2 is also sufficient to induce membrane curvature in $R$. sphaeroides. The protein forms hexagonally packed complexes, which are localized at high membrane curvature regions and, according to molecular dynamic simulation, could also induce membrane curvature [77, 81, 82]. The combined action of LH2 and RC-LH1-PufX would thus allow for the formation of spherical shaped chromatophores.

\section{Hijacking membrane remodeling: lessons learned from viral infection}

In addition to the aforementioned membrane-remodeling physiological events, intracellular membranes can also be reshaped during infection by peculiar viruses able to usurp host lipid metabolism to create new compartments dedicated to their replication (replication organelles) (Fig. 2). Viruses infecting a large variety of hosts,
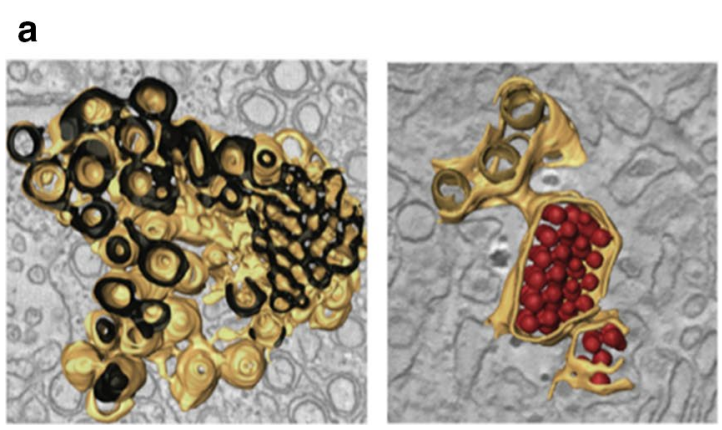

b

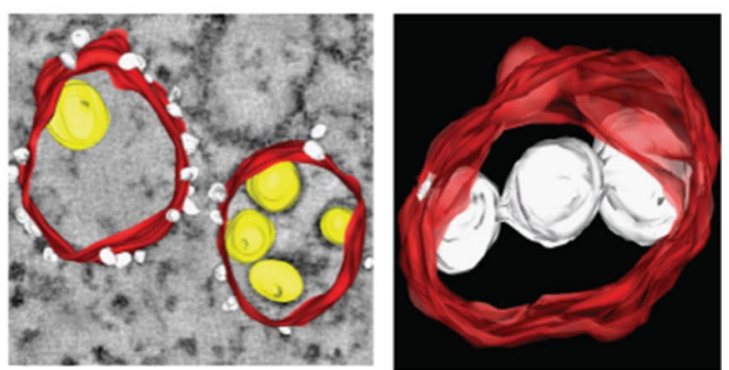

Fig. 2 Electronic tomography reconstruction of the replication organelles of some+RNA viruses. a Left: Interconnected reticular network induced by dengue virus infection. The cytosolic face of the intracellular membranes is shown in brown and the ER lumen in black. Right: Viral particles (red) found in continuous ER cisternae. ER membranes are colored in light brown and inner vesicle membranes in dark brown [86]. b Left: Surface model of Kunjin virus replication organelles; ER membranes are colored in red, ribosomes in white and viral RNA in yellow. Right: Vesicles (white) connected to each other and to the ER membranes (red) [87] 
ranging from bacteria and unicellular eukaryotes to vegetal and animal cells, have been described that trigger this phenomenon [83]. Among those, positive-sense single-stranded RNA viruses (+ RNA) infecting eukaryotic cells are the most studied. Because the +RNA of those viruses has the same sense as the cellular messenger RNA it is immediately translated when it reaches the cellular cytosol. Thus, viral proteins capable of modifying membrane curvature, which will be discussed in more detail in the following sections, are readily produced in the early infection stage $[84,85]$.

In addition, a correlation between membrane curvature and lipid biosynthesis during + RNA viral infection has been proposed [88]. Indeed, viral proteins modulating membrane curvature were also shown to promote the formation of membrane contact sites and the recruitment of host factors involved in lipid metabolism [89], in particular phosphatidylinositol-4-phosphate (PI4P) or phosphatidylethanolamine (PE) synthesis [90]. Interestingly, the accumulation of PIP4 or PE is often accompanied with an enrichment in sterol that might contribute to the stabilization of membrane curvature and is important for the replication of the virus [91].

In addition to + RNA viruses, other viruses containing double-stranded RNA (Reoviruses) as well as DNA viruses (Poxvirus, Vaccina virus, African swine fever virus, Frog Virus 3 and Paramecium Bursaria Chlorella Virus, giant Mimivirus Acanthamoeba polyphaga) also induce massive host membrane rearrangements. Although less studied, those viruses also rely on the production of proteins modifying the curvature of the host membrane [92, 93]. The membrane-enveloped double stranded RNA bacteriophages from the cystoviridiae family, such as phage $\phi 6$, are the only known enveloped phages and are evolutionarily related to the + RNA eukaryotic virus picornavirus [94]. They also produce proteins capable of bending the inner membrane of their hosts (Gram negative bacteria) which are necessary for virus replication [95].

In summary, certain viruses hijack the lipid metabolism of their hosts using specific proteins that modify membrane curvature and host co-factors to alter the lipid composition of the membrane to favor their own replication. However, how those factors are related to de novo membrane biosynthesis and viral replication organelles assembly remains elusive and should be further investigated.

\section{Inner membrane proliferation upon overproduction of some membrane proteins}

Overproduction of recombinant membrane proteins is usually difficult due to various limitations, including a shortage of membrane space needed to accommodate the produced proteins. In a few peculiar cases however, overproduction of membrane proteins, either in prokaryotic or eukaryotic cells, has revealed an unexpected and intriguing ability of cells to synthesize an excess of internal membranes (inner membrane proliferation). In fact, these newly synthesized inner membranes often contain large amounts of well-folded recombinant proteins, holding great promises for biotechnological applications. Since the pioneer observation of Weiner et al. [96], only a few dozen membrane-associated proteins from prokaryotic (Table 1) and eukaryotic (Table 2) origin have been described that trigger non-physiological lipid membrane proliferation or "inducible intracellular membranes" (Fig. 3).

From a morphological point of view, those inducible intracellular neo-membranes can be related to the bioenergetic compartments of $\alpha$-proteobacteria and mitochondria [100], and/or replication organelles of + RNA viruses [88]. Furthermore, similarly to those "natural" intracellular compartments most of the proteins triggering inducible intracellular membranes (Tables 1,2) also create zones with high membrane curvature [101]. For this reason, "natural" and "induced" intracellular membrane proliferation might share a more profound relation that goes beyond simple morphological resemblance.

\section{Mechanisms of protein-induced membrane curvature}

Modulation of membrane curvature is often at the midst of both physiological and induced membrane remodeling processes. The induced membrane proliferation upon protein overproduction has, however, the advantage of being decoupled from the cell physiological regulations. For this reason, we will examine the current knowledge on the mechanism of inner membrane proliferation, focusing on the influence of membrane curvature not only on membrane morphology but also on phospholipid biosynthesis. In particular, four important questions about inner membrane proliferation upon protein overproduction remain: (1) how can overproduced proteins induce the deformation of the inner membrane creating different morphologies; (2) what are the characteristics of the proteins triggering lipid biosynthesis and, thus, inner membrane proliferation; (3) how are protein overproduction and de novo phospholipid biosynthesis coordinated; and (4) can we find regulatory mechanisms conserved across evolution explaining internal membrane proliferation in both prokaryotic and eukaryotic cells.

In order to yield the observed morphologies (vesicles, tubules, stacks of flat membranes, etc.) listed in Tables 1 and 2 and illustrated in Fig. 3, proteins inducing inner membrane proliferation must modify membrane curvature by means of one (or the combination of several) of 
Table 1 Proteins triggering membrane proliferation in prokaryotes

\begin{tabular}{|c|c|c|c|c|c|c|c|}
\hline Protein & Type & Origin & Expressed & Morphology & $\begin{array}{l}\text { Protein } \\
\text { arrangement }\end{array}$ & Lipid composition & Refs. \\
\hline Fumarate Reductase & $\mathrm{TM}$ & E. coli & E. coli & Tubules & $\begin{array}{l}\text { Helical (10 units per } \\
\text { turn) }\end{array}$ & $\begin{array}{l}\text { CL enrichment } \\
(\sim 15 \% \mathrm{~mol})\end{array}$ & {$[96,116]$} \\
\hline $\begin{array}{l}\text { Succinate Dehydro- } \\
\text { genase }\end{array}$ & TM & E. coli & E. coli & Tubules and Vesicles & - & - & {$[117]$} \\
\hline Mannitol Permease & $\mathrm{TM}$ & E. coli & E. coli & Vesicles & - & - & {$[190]$} \\
\hline $\begin{array}{l}\text { P6 (sp6.6 gene } \\
\text { product) }\end{array}$ & $\mathrm{TM}$ & Phage PM2 & E. coli & Vesicles & $\begin{array}{l}\text { Unknown alone. } \\
\text { Cage-forming } \\
\text { protein associated } \\
\text { with P3 }\end{array}$ & - & {$[108]$} \\
\hline P9 and P12 & $\mathrm{TM}$ & Phage $\varphi 6$ & $\begin{array}{l}\text { P. syringae } \\
\text { E. coli }\end{array}$ & Vesicles & - & $\begin{array}{l}\text { CL enrichment } \\
(\sim 10 \% \text { mol in } \\
\text { P.pseudoalcaligenes } \\
\text { infected by phage } \\
\varphi 6)\end{array}$ & {$[3,112-114]$} \\
\hline $\begin{array}{l}\text { AlkB (alkane oxida- } \\
\text { tion system) }\end{array}$ & $\mathrm{TM}$ & P. oleovorans & E. coli & Vesicles & - & $\begin{array}{l}\text { CL enrichment (not } \\
\text { quantified) }\end{array}$ & [191] \\
\hline $\begin{array}{l}\text { Tsr chemotaxis } \\
\text { receptor }\end{array}$ & $\mathrm{TM}$ & E. coli & E. coli & $\begin{array}{l}\text { Inner membrane } \\
\text { invaginations }\end{array}$ & $\begin{array}{l}\text { Crystalline pseu- } \\
\text { dohexagonal ( } 3 \\
\text { dimers of Tsr per } \\
\text { repeating unit) }\end{array}$ & - & {$[125,128]$} \\
\hline $\begin{array}{l}\text { sn-glycerol-3-P } \\
\text { acyltransferase }\end{array}$ & $\mathrm{TM}$ & E. coli & E. coli & Tubules & $\begin{array}{l}\text { Helical (6 dimers per } \\
\text { turn) }\end{array}$ & $\begin{array}{l}\text { No changes. } \\
\text { Dependent on } \\
\text { phage heat shock } \\
\text { protein (PspA). }\end{array}$ & {$[120,121,192]$} \\
\hline $\begin{array}{l}\text { (b subunit of) } F_{0} F_{1} \\
\text { ATP synthase }\end{array}$ & $\mathrm{TM}$ & E. coli & E. coli & Tubules and vesicles & $\begin{array}{l}\text { Unknown. Dimer } \\
\text { formation }\end{array}$ & $\begin{array}{l}\text { CL enrichment } \\
(\sim 24 \% \mathrm{~mol})\end{array}$ & {$[6,122,123,149]$} \\
\hline P3A & M & FMDV & E. coli & Onion-like vesicles & $\begin{array}{l}\text { Unknown. Possible } \\
\text { oligomerization? }\end{array}$ & - & [97] \\
\hline Caveolin-1 & $M$ & H. sapiens & E. coli & Vesicles & $\begin{array}{l}\text { Well-defined supra- } \\
\text { molecular cage } \\
\text { (160 monomers } \\
\text { per cage) }\end{array}$ & $\begin{array}{l}\text { PG and lysophos- } \\
\text { pholipids } \\
\text { enrichment (not } \\
\text { quantified) }\end{array}$ & {$[104,105]$} \\
\hline MurG & M & E. coli & E. coli & Vesicles & - & $\begin{array}{l}\text { CL enrichment } \\
(\sim 22 \% \mathrm{~mol})\end{array}$ & {$[137]$} \\
\hline LpxB & $M$ & $\begin{array}{l}\text { E. coli and } \\
\text { H. influenzae }\end{array}$ & E. coli & Tubules and vesicles & - & $\begin{array}{l}\text { PG and CL enrich- } \\
\text { ment (not quanti- } \\
\text { fied) }\end{array}$ & {$[138]$} \\
\hline PmtA & M & A. tumefacensis & A. tumefacensis & Vesicles & - & $\begin{array}{l}C L \text { needed for mem- } \\
\text { brane proliferation } \\
\text { (not quantified) }\end{array}$ & [139] \\
\hline alMGS & M & A. laidlewii & E. coli & Vesicles & - & $\begin{array}{l}\text { PG and CL enrich- } \\
\text { ment (not quanti- } \\
\text { fied) }\end{array}$ & {$[140-142,193]$} \\
\hline
\end{tabular}

the general mechanisms previously proposed (molecular motors, supramolecular scaffolding, asymmetric membrane interaction, wedging, see Fig. 1). However, the production of a pulling or pushing force will not be discussed in this section since none of the reviewed proteins is a molecular motor, nor a scaffolding protein interacting with any molecular motor.

\section{Protein-protein supramolecular interactions}

The construction of a 3D supramolecular scaffold via supramolecular interactions is an efficient way of controlling cell membrane curvature and is used by many proteins involved in membrane remodeling processes (e.g. endocytosis, fission, motility, membrane trafficking, etc.) [102]. Most of the proteins inducing intracellular membrane proliferation (Tables 1 and 2) have been described to form supramolecular assemblies around the lipid bilayer. The membrane curvature and, consequently, the inner membrane morphology 
Table 2 Proteins triggering membrane proliferation in eukaryotes

\begin{tabular}{|c|c|c|c|c|c|c|}
\hline \multirow[t]{2}{*}{ Protein } & \multicolumn{6}{|l|}{ Organism } \\
\hline & Origin & Expressed & Morphology & Target organelle & Observations & Refs. \\
\hline HMG-COA & $\begin{array}{l}\text { S. cerevisiae } \\
\text { S. pombe }\end{array}$ & S. cerevisiae & $\begin{array}{l}\text { "karmellae" stacked mem- } \\
\text { branes around nucleus }\end{array}$ & ER & $\begin{array}{l}\text { Soluble domain not } \\
\text { required. } \\
\text { Transmembrane helix alone } \\
\text { not sufficient. }\end{array}$ & {$[98,135,150]$} \\
\hline Cytochrome b5 & R. norvegicus & S. cerevisiae & $\begin{array}{l}\text { "karmellae" stacked mem- } \\
\text { branes around nucleus }\end{array}$ & $\mathrm{ER}$ & $\begin{array}{l}\text { Transmembrane domain } \\
\text { disturbed by proline } \\
\text { hinders membrane } \\
\text { proliferation }\end{array}$ & {$[132]$} \\
\hline Cytochrome P450 & C. maltosa & S. cerevisiae & $\begin{array}{l}\text { "karmellae" stacked } \\
\text { membranes around } \\
\text { nucleus + Tubules }\end{array}$ & ER & $\begin{array}{l}\text { Minimum domain 1-33: } \\
\text { contains hydrophobic } \\
\text { helix and charged resi- } \\
\text { dues flanking it. }\end{array}$ & {$[129,134,220-222]$} \\
\hline PMA2 ( $\mathrm{H}^{+}$ATPase $)$ & S. cerevisiae & S. cerevisiae & Tubules & ER & - & {$[223]$} \\
\hline $\mathrm{RRp}-180 \mathrm{kDa}$ & C.lupus & S. cerevisiae & $\begin{array}{l}\text { "karmellae" stacked mem- } \\
\text { branes around nucleus }\end{array}$ & ER & $\begin{array}{l}\text { RBS not required for mem- } \\
\text { brane proliferation. } \\
\text { Increase of secretory } \\
\text { pathway }\end{array}$ & {$[130,224]$} \\
\hline $\mathrm{D}_{25}$ receptor & H. sapiens & P.pastoris & $\begin{array}{l}\text { "karmellae" stacked mem- } \\
\text { branes around nucleus }\end{array}$ & ER & - & {$[225]$} \\
\hline sk2 Channel & H. sapiens & P.pastoris & $\begin{array}{l}\text { "karmellae" stacked mem- } \\
\text { branes around nucleus } \\
\text { and ER }\end{array}$ & ER & - & {$[226]$} \\
\hline $\mathrm{B}_{2}$ receptor & H. sapiens & P.pastoris & $\begin{array}{l}\text { "karmellae" stacked mem- } \\
\text { branes around nucleus }\end{array}$ & ER & - & {$[227]$} \\
\hline LaminB receptor & G. domesticus & S. cerevisiae & $\begin{array}{l}\text { "karmellae" stacked mem- } \\
\text { branes around nucleus }\end{array}$ & ER & - & [228] \\
\hline Pex12p & S. cerevisiae & S. cerevisiae & Multilayered membranes & Peroxisome & $\begin{array}{l}\text { Observed morphology is } \\
\text { dependent on expression } \\
\text { level }\end{array}$ & {$[131]$} \\
\hline Pex15p & S. cerevisiae & S. cerevisiae & Multilayered membranes & Peroxisome, ER & $\begin{array}{l}\text { ER to peroxisome transport } \\
\text { blocked }\end{array}$ & {$[210]$} \\
\hline $2 B C$ & Poliovirus & S. cerevisiae & Vesicles & Vacuole & ER transport blocked & {$[99]$} \\
\hline 36 k protein IRV & $\begin{array}{l}\text { Carnation Italian } \\
\text { Ringspot Virus }\end{array}$ & S. cerevisiae & Vesicles & Mitochondria & - & [133] \\
\hline Protein A & Flock House Virus & S. cerevisiae & Vesicles & Mitochondria & $\begin{array}{l}\text { Retargeting of protein A } \\
\text { to ER possible with ER } \\
\text { specific sequence }\end{array}$ & {$[151]$} \\
\hline
\end{tabular}

observed in electronic microscopy will depend on the shape, nature and concentration of monomers constituting the supramolecular scaffold.

\section{Caveolin}

Heterologously expressed caveolin-1 in E. coli cells is perhaps the best-characterized example of how a single membrane protein can shape the morphology of the newly synthesized lipid bilayer. Caveolin-1 is a scaffolding protein involved in the formation of vesicles (caveolae) arising from the plasma membrane of eukaryotic cells [103]. The formation of heterologous-caveolae (h-caveolae) derived from E.coli inner membrane is linked to the assembly of caveolin-1 into a supramolecular cage [104].
This cage contains around 160 caveolin- 1 monomers and is similar in structure and size to eukaryotic caveolae. The three membrane-interacting domains and the oligomerization domain of caveolin-1 are required for inner membrane proliferation [105]. The formation of a regular and well-defined caveolin-1 scaffold seems to impose a strong local curvature on the cell membrane, causing the budding of vesicles coated with caveolin-1, and triggering the biosynthesis of phospholipids. As a consequence, monodisperse vesicles of the same size as those found in eukaryotic cells, accumulate in the E.coli cytosol. 

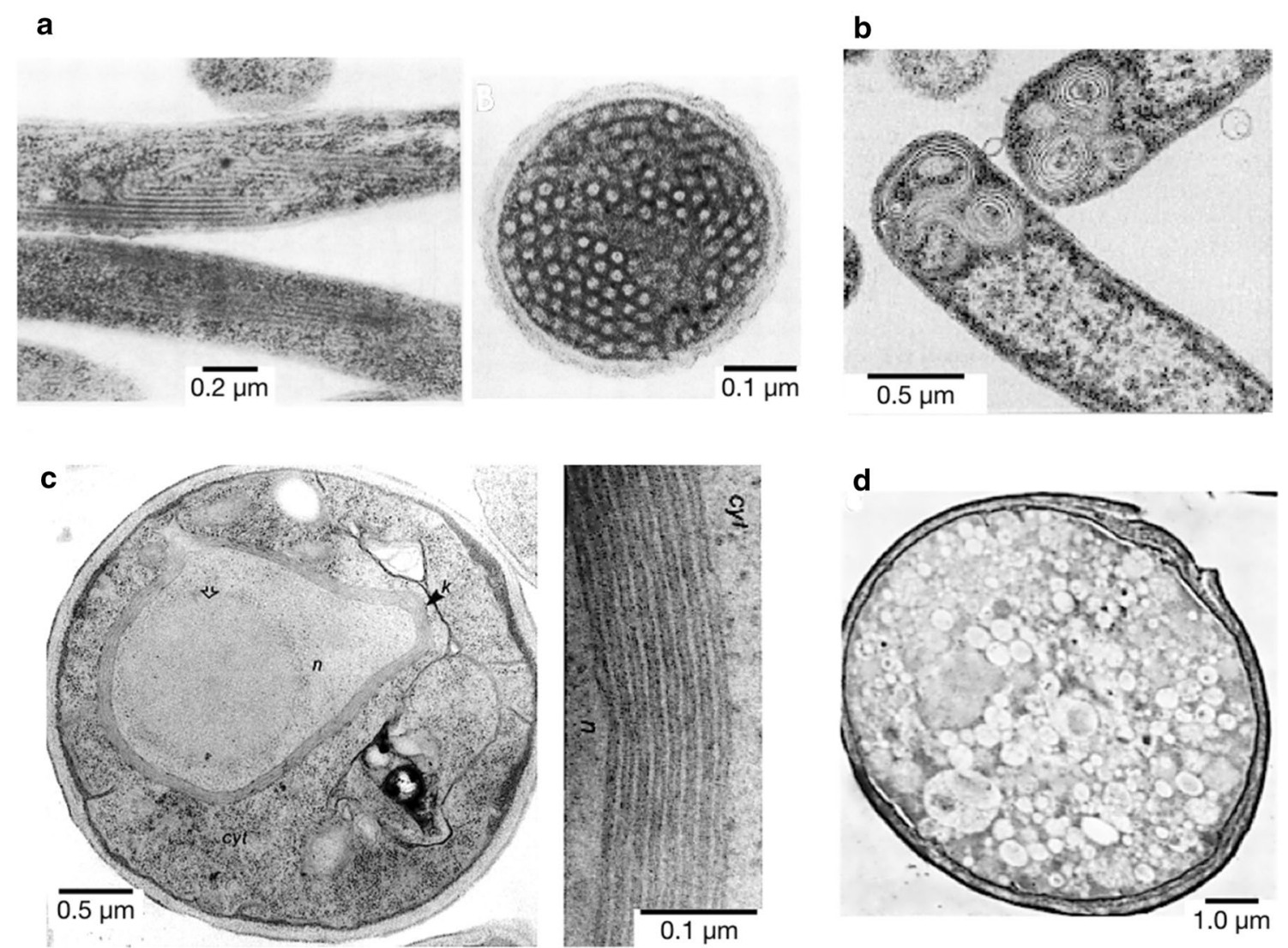

Fig. 3 Negative-staining TEM pictures of some examples of inner membrane proliferation upon membrane protein overproduction. a Longitudinal (left) and transversal (right) sections of E. coli inner membrane tubules after fumarate reductase overproduction [96]. b Onion-like vesicles formed upon overproduction of protein 3A of Foot and Mouth Disease Virus (FMDV) [97]. c S. cerevisiae cell with the cytosol (cyt), nucleus ( $n$ ) and the stacked membranes "Karmellae" ( $\mathrm{k}$ ) around the nucleus ( $\mathrm{n}$ ) (left) and detail of those membranous structures (right) after 3-Hydroxy-3-methylglutaryl-CoA reductase (Hmg-CoA) overproduction [98]. d Vesicles formed in S. cerevisiae upon overproduction of poliovirus protein 2BC [99]

\section{Non-structural phage proteins}

The overproduction of phage PM2 protein P6 represents another instance of membrane proliferation presumably induced by a supramolecular cage [106]. Although the structure of P6 has not been studied when it is overproduced in $E$. coli membrane, the structure of the entire PM2 phage has been determined by crystallography. This phage, which infects Gram negative bacteria from the Pseudoalteromonas genus [107], is composed of an icosahedral protein capsid containing a lipid membrane that encloses a double stranded DNA (dsDNA). P6 interacts with the viral lipid membrane but it is not a capsid forming protein. It associates with the $\mathrm{P} 3$ protein to form a well-ordered supramolecular structure that confers icosahedral symmetry to the lipid bilayer. P6 is inserted at the edges, whereas two P3 dimers stabilize the facets of the icosahedra. In other words, P6 is in charge of "welding" the lipid bilayer to create the icosahedral vertices. In the absence of P3, P6 is still able to impose a curvature to the E.coli inner cell membrane, producing vesicles [108]. Foot-and-mouth disease virus (FMDV) protein $3 \mathrm{~A}$ is another example of a viral protein modulating membrane curvature. During the early stages of infection, FMDV, like other + RNA virus, remodels the ER membrane of its hosts (mammalian cells) to form the viral replication organelle, which provides a platform for viral RNA replication [109]. The interaction between the non-structural viral proteins (such as FMDV protein 3A) and the host phospholipids seems to be the trigger for host membrane remodeling [110]. When overexpressed in E.coli, FMDV protein 3A alone is able to deform the inner membrane, producing onion-like vesicles instead of its characteristic replication organelles [97]. The lack of other viral proteins or the differences in the nature and composition of phospholipids between eukaryotes and prokaryotes might explain this change in morphology. The precise mechanism of membrane deformation by FMDV protein $3 \mathrm{~A}$ is unknown, but it requires the central 
amphipathic helix of the protein, together with the two cytosolic $\mathrm{N}$ - and C-terminal domains [111], which might interact with other viral proteins or induce oligomerization with other copies of FMDV 3A. Similarly, phage $\phi 6$ is a dsRNA bacteriophage, evolutionarily related to eukaryotic + RNA viruses ("Inner membrane proliferation upon overproduction of some membrane proteins" section), which infects Gram negative bacteria from the Pseudomonas genus. The overproduction of P9 and P12 phage $\phi 6$ proteins induce the proliferation of intracellular vesicles in E. coli and P. syringae [3, 112-114]. Both proteins (P9 and $\mathrm{P} 12$ ) are required to create the lipidic envelope of the phage [115]. P9 is a transmembrane protein, which is produced in large quantities in the early stages of infection and inserted in the inner membrane [11, 95, 112]. P12 is a non-structural protein and its role in the creation of the viral envelope is unknown, although it seems to somehow inhibit the degradation of P9 by the host proteolytic enzymes $[112,114]$.

\section{Proteins involved in bioenergetic metabolism}

Overexpression of some enzymes involved in energetic metabolism also induce membrane proliferation in $E$. coli. For example, fumarate reductase results in the formation of an array of densely packed lipid tubules in $E$. coli cytosol, that are severed from the inner membrane [116]. These lipid tubules are stabilized by a scaffold of fumarate reductase packed in a regular helical configuration containing 10 proteins per helix turn [96]. However, those tubules do not seem to fulfil any biological function, because the electronic transport chain is completely absent from the membrane expansions. Similar tubules are also observed when succinate dehydrogenase is overexpressed in E.coli [117]. Probably, the mechanism of tubule stabilization is similar to that observed with fumarate reductase due the structural and functional similarities between these two enzymes $[118,119]$. Although the supramolecular packing of succinate dehydrogenase has not been studied in depth, the authors observed different morphologies (tubules or vesicles) depending on the expression level of the protein [117]. The supramolecular array of succinate dehydrogenase necessary to stabilize the tubule morphology might only be formed if the protein is produced at sufficient level. Thus, below a critical concentration, succinate dehydrogenase is still able to deform the membrane and yield vesicles but it is not capable of maintaining the tubule structure.

The $s n$-Glycerol-3-P acyltransferase is another example of protein inducing membrane tubules formation upon overproduction [120]. The individual molecules of sn-Glycerol-3-P acyltransferase are arranged in dumbbell-shaped dimers, which are packed in a left-handed helix along the tubule axis [121]. The association of six
sn-Glycerol-3-P acyltransferase dimers completes a helix turn.

The whole $\mathrm{F}_{0} \mathrm{~F}_{1}$ ATP synthase [122], and more efficiently, its b subunit alone [123], also produce vesicles and tubules detached from the inner membrane when overexpressed in E. coli. There is no data about the supramolecular packing of the $b$ subunit of $\mathrm{F}_{\mathrm{o}} \mathrm{F}_{1}$ ATP synthase in the lipid bilayer. Nevertheless, interactions between adjacent proteins seem to be important, since the removal of the cytosolic dimerization domain of the b subunit of $\mathrm{F}_{\mathrm{o}} \mathrm{F}_{1}$ ATP synthase (residues from 53 to 122 [124]) inhibits tubules formation [123].

\section{The serine chemotaxis receptor}

The overproduction of the serine chemotaxis receptor (Tsr) from E. coli also triggers inner membrane proliferation [125]. Tsr is a transmembrane protein with a periplasmic domain that binds small molecules (Tsr is specific to serine) and a cytoplasmic domain associated with the adaptor protein CheW and the kinase ChewA [126]. In normal physiological conditions, cytoplasmic domains of adjacent Tsr form trimers of Tsr dimers, and self-assemble in two-dimensional clusters concentrated at the bacterial cell poles [127]. When overproduced, Tsr is also organized as trimeric assemblies of dimers [125]. However, because Tsr amounts are significantly increased, the two-dimensional clusters of Tsr can interact with each other creating a three-dimensional pseudo-hexagonal crystalline array that folds the inner membrane [125]. If this crystalline array is destroyed, e.g. by overproducing Tsr partners (ChewA and ChewW) at the same levels as Tsr, membrane proliferation is inhibited, even at high Tsr concentration in the membrane [128]. This result suggests that the high membrane curvature imposed by the crystalline array of Tsr is necessary to trigger phospholipid biosynthesis.

\section{Examples in eukaryotic cells}

Membrane curvature induction by protein overproduction is not restricted to prokaryotic hosts and has also been observed in eukaryotic cells (Table 2). Unfortunately, structural data on the arrangement of the recombinant proteins in the newly synthesized inner membranes are lacking. Still, there are some hints pointing to the presence of supramolecular scaffolds. For example, the minimal protein fragment of cytochrome P450 NADPH reductase and of canine ribosome receptor (RRp), which both induce membrane proliferation, include the charged residues flanking the hydrophobic transmembrane domain, as described for prokaryotic proteins $[129,130]$. Moreover, it has been reported that, in some cases, the morphology of the newly produced membranes depends on the amount of overproduced 
membrane protein [131]. Disturbance of the 3D structure of the protein by introducing proline mutations [132], GFP fusions in critical positions [133], partially misfolding the proteins [134] or by deleting oligomerization domains [135], results in an altered morphology of the inner membrane structures. In addition, protein-protein supramolecular interactions are also required for inner membrane proliferation in mammalian cells [136]. The production of chimeras with cytochrome b5 transmembrane domains and a dimerization-prone GFP changes the morphology of proliferating membranes in the ER from stacks of membranes to a bi-continuous phase with cubic symmetry. Furthermore, membrane proliferation is also induced by fusing dimerization prone GFP to ER resident proteins; whereas each proteins overproduced separately, do not trigger membrane proliferation. Taken together, these features are in line with the observations made in prokaryotes, and suggest that protein-protein supramolecular interactions are a ubiquitous mechanism to control membrane curvature cells.

\section{Asymmetric interaction of proteins with only one leaflet of the lipid bilayer}

Besides the formation of a supramolecular scaffold, the asymmetric insertion of a membrane protein into one leaflet of the lipidic bilayer can lead to a modification of the membrane curvature. Such a mechanism has been hypothesized for monotopic proteins inducing membrane proliferation such as MurG [137], LpxB [138] and PtmA [139] and confirmed by sequence comparison and in silico studies of alMGS [140, 141]. In addition, PtmA and alMGS have been purified and their ability to remodel synthetic liposomes into lipid tubules has also been demonstrated in vitro $[139,141,142]$.

\section{Insertion of wedge-shaped proteins into the membrane}

The insertion of wedge-shaped proteins into the lipid bilayer can also modulate membrane curvature [143]. Most transmembrane domains of membrane proteins introduce a packing mismatch in the lipid bilayer, which alters the membrane curvature. A well-known example of this mechanism is the wedge-shaped bacteriorhodopsin, a light-driven proton pump expressed in archaebacteria under anaerobic conditions. Bacteriorhodopsin is found in highly curved, specialized membrane microdomains (purple membranes), in which it forms trimeric, hexagonal units packed in a 2D crystalline lattice together with archaeal lipids [144, 145]. These lipids also contribute to the 2D crystalline packing as bacteriorhodopsin mutants with a constitutive wedge-shaped structure still need a specific lipidic environment to induce membrane curvature $[146,147]$. Therefore, both phospholipid composition and protein tertiary 3D structure work together to modulate the membrane curvature in purple membranes.

It is remarkable how newly produced inner membranes of prokaryotes are enriched in cone-shaped non-bilayer forming lipids (CL or lyso-phospholipids) (Table 1). Similarly to wedge-shaped proteins, those cone-shaped phospholipids can also modulate membrane curvature. Their effect is expected to be less important than those induced by proteins, but not be negligible. Indeed, eukaryotic caveolae are enriched in phosphatidylinositol (PI) and cholesterol, which are important for the organization of lipid rafts. Similarly, $E$. coli adapts the phospholipid composition of $h$-caveolae replacing anionic PI by PG and non-bilayer forming cholesterol for lyso-phospholipids, only found in trace concentration in normal physiological conditions [104]. Symmetrically, in silico simulations show that membrane bending is facilitated by the incorporation in the lipid bilayer, of CL at levels similar to the ones observed in cases of membrane proliferation upon protein overproduction [148]. Furthermore, two examples have recently shown the importance of $C L$ enrichment in the morphology of overproduced inner membranes. Firstly, E. coli mutants with reduced amounts of CL ( $2 \%$ vs. $24 \%$ mol in wild type) changed the organization of the produced inner membrane from organized tubules to onion like vesicles upon overproduction of the $b$ subunit of $\mathrm{F}_{0} \mathrm{~F}_{1}$ ATP synthase [149]. E. coli mutants completely depleted of CL confirmed this change of morphology and, in addition, were less efficient in triggering the proliferation of inner membranes [149]. Secondly, CL is necessary for the formation of inner membrane vesicles by PmtA, as it has been demonstrated both in vitro and in vivo [139]. In vitro, PmtA is unable to deform synthetic liposomes lacking CL and no vesicle-like structures where observed in vivo after PmtA overproduction in CL-deficient bacterial mutants. Together, both examples illustrate the central role of $C L$ in the proliferation of inner membranes.

The phospholipid composition of the newly produced membranes in eukaryotes is largely unknown. To our knowledge, only a few indirect observations are available. For instance, "Karmellae" (or stacks of membranes surrounding the nucleus) produced by overproduction of 3-Hydroxy-3-methylglutaryl-CoA reductase (Hmg-CoA) seem to be enriched in neutral lipids, e.g. sterols [150]. However, no lipid quantification or identification was performed and this observation is only derived from a preferential staining with Nile Red, which has low specificity and indiscriminately stains all cell membranes. As previously discussed, the expression of some viral proteins, (2BC from poliovirus, $36 \mathrm{~K}$ 
from Carnation Italian ringspot virus or protein A from Flock House virus) also induce different types of membrane in yeast (Table 2) [99, 133, 151]. In these cases, the creation of sterol-rich microdomains are required to assist membrane-remodeling proteins to effectively modulate membrane curvature [152, 153]. It is worth mentioning here the bacteriophage $\phi 6$, which induces a ninefold increase in CL levels in infected bacteria [115], reinforcing the importance of CL in intracellular membrane proliferation in prokaryotes.

\section{Summary and final considerations about protein-induced membrane curvature}

Most of the proteins triggering membrane proliferation are able to locally modulate the membrane curvature. Independently of the precise mechanism involved in the creation of highly curved membrane microdomains, some common features are found in many of the reviewed proteins:

- The production of the membrane-interacting domains alone is not sufficient to modulate the membrane curvature. Additional protein domains are often required, suggesting that the induction of highly curved membrane microdomains is not a general consequence of membrane protein overproduction and insertion into the intracellular membrane.

- In some cases, the membrane curvature depends on the concentration of the overproduced proteins. A certain threshold of overproduced protein is necessary to trigger membrane proliferation. Different levels of protein concentration can lead to different membrane morphologies in vivo.

- The membrane curvature induced by proteins is often accompanied by a production of non-bilayer forming phospholipids (e.g. CL). These phospholipids can assist in the creation and stabilization of curved membrane domains and favor some membrane morphologies.

The membrane morphologies observed in vivo (vesicles, tubules, flat stacks of membranes, etc.) depend on the balance between protein 3D structure of the recombinant protein, its concentration, and the phospholipid membrane composition. Recently, Bonazzi et al. attempted for the first time to theoretically model the membrane morphology produced by arc-shaped proteins (or protein assemblies) modifying membrane curvature [154]. This theoretical model not only predicts the dependence of membrane morphology on protein concentration but also the existence of a vesicle-to-tubule transition, observed for some proteins listed in Tables 1 and 2. Furthermore, tubule-shaped membranes are formed independently of the shape of the protein when the concentration of proteins is high enough to cover more than $40 \%$ of the membrane surface area, which explains the prevalence of tubular membrane structures upon protein overexpression. This study strongly suggests that the mechanisms involved in membrane curvature induction and, as a consequence, the morphology observed upon protein overproduction, are predictable and determined by physical laws.

\section{Influence of membrane curvature on phospholipid biosynthesis in prokaryotic cell}

The viability of bacteria directly depends on their ability to maintain membrane homeostasis and the electrochemical gradient in response to different environmental conditions. Lipid biosynthesis and modification are the most energy-intensive processes of membrane homeostasis, therefore it is not surprising that lipid metabolism is tightly regulated both transcriptionally and enzymatically [155]. Impressively, proteins discussed in this review have found a way to hijack this vital regulation, forcing bacteria to produce increased amounts of inner membranes.

Because fatty acid and phospholipid biosynthesis are coupled in $E$. coli, we will focus exclusively on the regulation of the biosynthesis of phospholipid polar heads, overlooking fatty acid metabolism [155]. Phospholipid metabolism and its regulation in prokaryotes (Fig. 4) have been extensively studied [156-158]. Still, even in the archetypical E.coli, many pieces are lacking to construct a complete vision of lipid metabolism. One of these missing pieces is how (membrane) protein expression is synchronized with lipid biosynthesis. Protein synthesis stopped after inhibition of lipid synthesis and re-started when lipid metabolism was restored [159-161]. Consequently, it appears that protein and lipid metabolisms are intimately connected and cross-regulated. However, the nature or mechanism of this regulation is unknown, even though some clues point to a regulation via multiple stress pathways [162-164].

\section{The importance of phospholipid homeostasis}

E. coli maintains a constant ratio between zwitterionic phosphatidylethanolamine (PE), which accounts for about 75\% wt. of total phospholipids, and anionic PG and $\mathrm{CL}$, whose relative amounts depend on the physiological state (log- or stationary-phase) of the cells [155]. A feedback mechanism between the cross-regulated enzymes controlling the synthesis of PE and PG/CL (PssA and PgsA, respectively) maintains the homeostasis in phospholipid headgroup diversity (Fig. 4). PssA is a monotopic membrane protein that acts as a sensor, detecting 


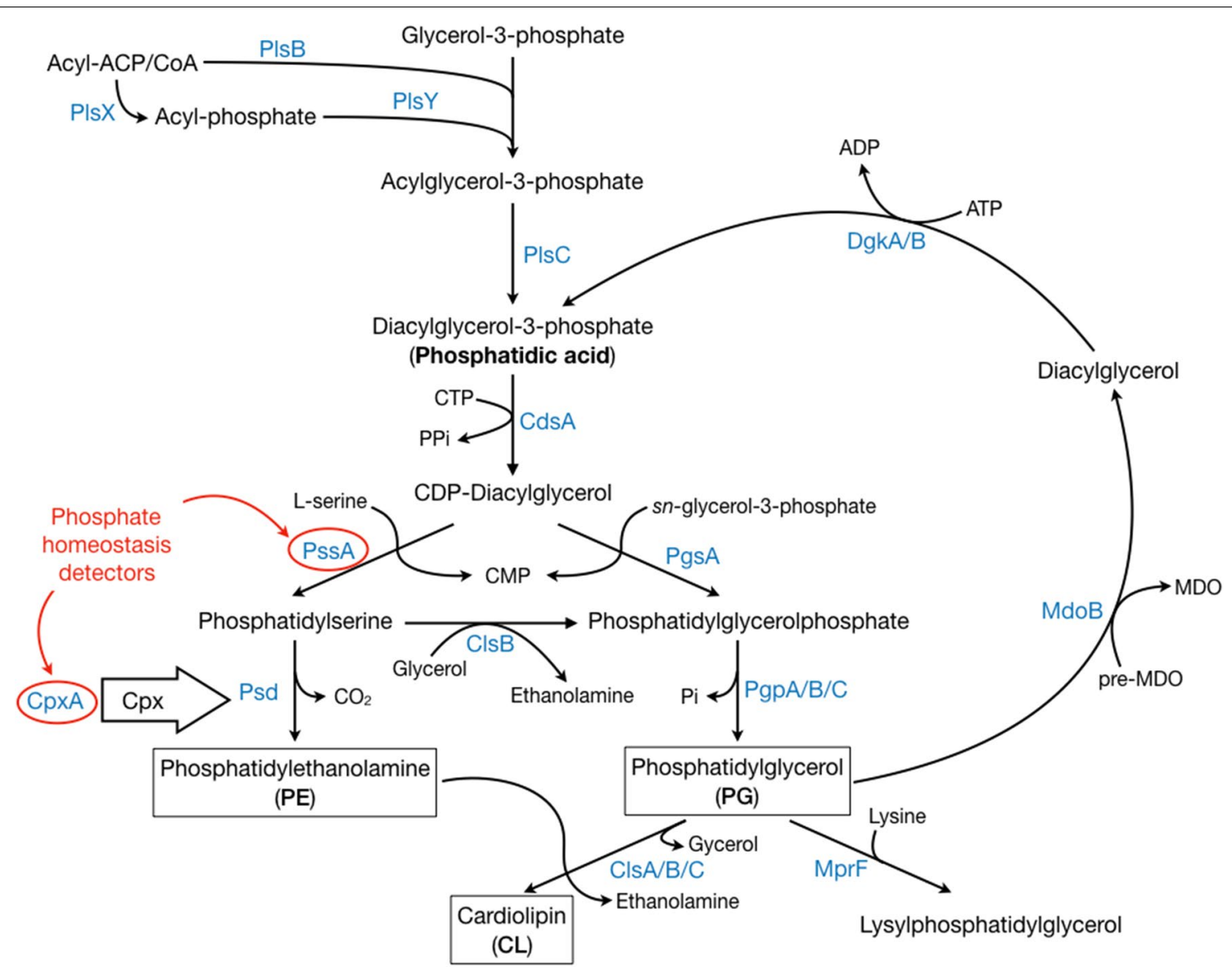

Fig. 4 Brief overview of phospholipid polar head homeostasis in E. coli. Marked in red are the known membrane composition sensors. CTP: Cytosine TriPhosphate. CMP: Cytosine MonoPhosphate. MDO: Membrane Derived Oligosaccharides

changes in relative phospholipid composition (PE vs. $\mathrm{PG} / \mathrm{CL}$ ) in the lipid bilayer $[165,166]$. It is active when associated with anionic phospholipids (PG and CL) and catalyzes the synthesis of PE. On the contrary, when anionic phospholipids become less available, PssA is deactivated, causing PgsA metabolic route to accelerate and to increase the synthesis of PG and CL.

Besides the aforementioned enzymatic regulation, phospholipid homeostasis is also subject to genetic control. Alterations in phospholipid composition stimulate the activation of several stress response pathways that ensure the maintenance of the bacterial envelope integrity ( $\sigma^{\mathrm{E}}, \mathrm{Cpx}, \mathrm{Bae}$ and Rcs) (Fig. 4) [167]. Even though all these regulation pathways are entangled, the Cpx system is of particular interest for phospholipid homeostasis in E. coli [164]. It activates the transcription of more than 100 genes, especially genes coding for inner membrane proteins and phospholipid metabolism, including Psd (an enzyme involved in the synthesis of PE, Fig. 4) [168-170]. Furthermore, the Cpx regulation pathway is controlled by CpxA, a transmembrane protein kinase located in the
E. coli inner membrane, sensitive to modifications of the relative concentrations of anionic phospholipids in the lipid bilayer [171].

It seems clear that any alteration in the inner membrane phospholipid balance is compensated by the biosynthesis of the complementary type of phospholipids, either via enzymatic and/or genetic regulation. The enrichment in anionic phospholipids (especially CL) observed in most of the protein-triggered inner membrane proliferation (Table 1), most likely represents such an alteration. The constant biosynthesis of membrane proteins continuously alters phospholipid homeostasis and pushes E. coli to produce new phospholipids. The enrichment for specific phospholipids could be explained either by a selective interaction of the overproduced protein with the phospholipid type (PE or PG/CL), or by the creation of membrane microdomains with impaired accessibility to the homeostasis membrane sensors. 


\section{Electrostatic interactions between anionic phospholipids} and positively charged proteins

Overproduction of a membrane protein able to selectively bind anionic lipids, such as CL, could create a phospholipid imbalance in the inner cell membrane. Evidences supporting this hypothesis have been obtained in the case of the monotopic glucosyltransferase alMGS [140]. The alMGS domains that interact with phospholipids are enriched in positively charged amino acids [141], suggesting that they may selectively bind anionic phospholipid through electrostatic interactions. Indeed, the capacity of alMGS to alter phospholipid metabolism through its capacity to bind anionic phospholipids was later confirmed [142]. In addition, when overproduced, alMGS displaces the cyclopropane fatty acid synthase (CFA synthase) from its membrane binding site, inhibiting the synthesis of cyclopropanated fatty acids. Finally, phospholipid biosynthesis and alMGS overproduction are linked, as the supplementation of the culture media with lipid metabolism precursors leads to increased amounts of inner membranes with a concomitant increase in alMGS production [142]. Finally, alMGS overproduction also activates the $\sigma^{\mathrm{E}}$ and $\mathrm{Cpx}$ envelope stress responses, which can activate phospholipid metabolism as discussed in "The importance of phospholipid homeostasis" section. Besides alMGS, all of the monotopic membrane proteins listed in Table 1 (MurG, LpxB, caveolin-1 and PmtA) are known to bind to the lipid bilayer via electrostatic interactions with anionic phospholipids [104, 137-139]. Electrostatic interactions with transmembrane proteins have been less studied. Nevertheless, the activity of many respiratory complexes often depends on CL concentration [172]. Thus, it is not surprising that CL has been found to selectively interact with succinate dehydrogenase and $\mathrm{F}_{0} \mathrm{~F}_{1}$ ATP-synthase [173, 174]. Indeed, it was recently demonstrated that the mitochondrial $\mathrm{F}_{0} \mathrm{~F}_{1}$ ATP-synthase possesses a CL interaction site, conserved between yeast and bovine, which is enriched in positively charged amino acids $[175,176]$.

The presence of positively charged residues flanking transmembrane domains in the cytosolic leaflet of E.coli inner membrane is not, however, an exclusive feature of proteins triggering inner membrane proliferation. In fact, the "positive charges inside" rule [177], is a highly conserved mechanism to control the orientation of membrane proteins in the inner membrane [178]. This "positive charges inside" rule is conserved in most membrane proteins, not only in $E$. coli, but also in other prokaryotes and eukaryotes [179], while intracellular membrane proliferation has only been observed with a dozen of specific membrane proteins. To determine whether proteins able to induce membrane proliferation display specific charges distribution, we calculated the surface electrostatic potential of the proteins listed in Table 1 for which a structure is available in the PDB. Those proteins present a positive electrostatic lobe located nearby the phospholipid polar heads in the cytosolic leaflet of the inner membrane (Fig. 5a). However, this feature is far from being limited to the proteins inducing membrane proliferation. Indeed, MsbA and G3P transporter, two proteins that do not trigger intracellular membrane proliferation [180], also exhibit a marked positive electrostatic lobe near the cytosolic leaflet of the inner membrane (Fig. 5b). In conclusion, this positive electrostatic lobe is probably useful for membrane association and/or insertion in the correct orientation, but it is not sufficient per se to trigger inner membrane proliferation.

\section{Formation of $\mathrm{CL}$ microdomains}

An alternative explanation for the perturbation of phospholipid homeostasis in a reduced accessibility of certain type of phospholipids to the membrane homeostasis sensors, that could be a consequence of lipid microdomains formation. Lipid rafts enriched in sterols, sphingolipid and some proteins are a well-established membrane organization element in eukaryotic membranes [185]. The existence of membrane lipid microdomains, analogous to the lipid rafts of eukaryotes, has also been reported in prokaryotes [186]. These membrane microdomains associate with specific membrane protein complexes and are enriched in particular lipids (notably CL) $[66,158]$. Moreover, the spontaneous breaking of membrane symmetry with subsequent enrichment in CL in areas of high negative curvature has been theoretically modeled and also experimentally observed in E. coli membranes [148, 187, 188]. Very recently, this CL clustering and enrichment of highly curved membrane areas has been experimentally quantified [189]. It should be noted that in both theoretical and experimental designs an external force is necessary to impose high membrane curvature, as a mere accumulation of CL alone is not sufficient to curve the membrane enough to induce further CL clustering.

In this regard, the insertion of a membrane protein (or supramolecular complex of proteins) inducing a high local curvature would be needed to provide the necessary force to bend the membrane and induce CL clustering. This could in turn lead to an anionic phospholipid depletion in the non-curved zones of the membrane, which will subsequently be detected by the phospholipid homeostasis sensors as a signal to start lipid biosynthesis. Then, the newly synthesized lipid membranes would allow for more membrane protein insertion, thus, closing the cycle (Fig. 6). As previously discussed 
a

MurG

Periplasm

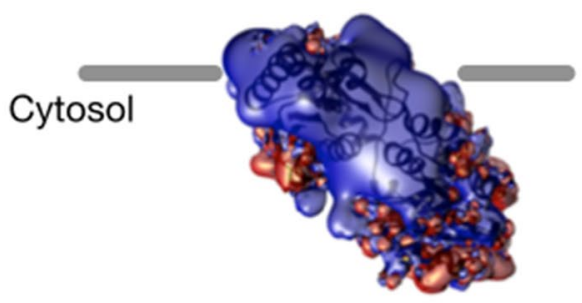

C

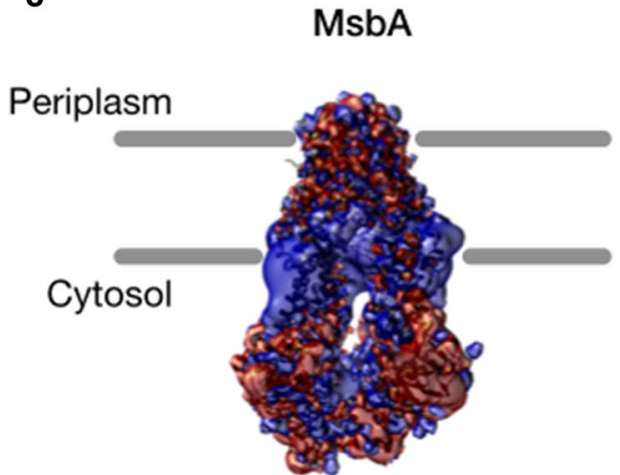

b

Fumarate reductase

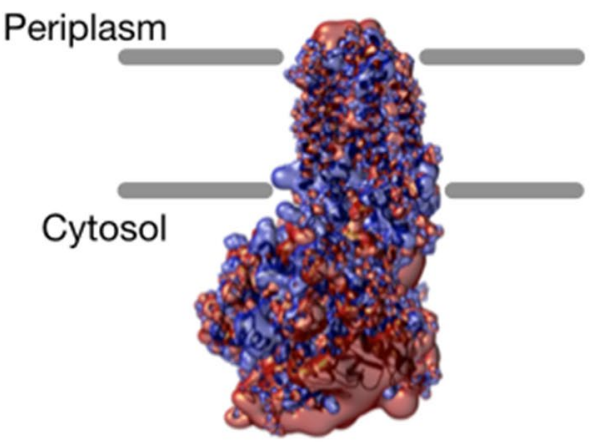

d

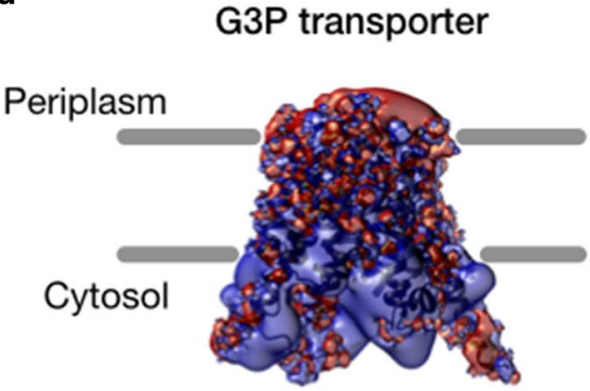

Fig. 5 Isopotential electrostatic surfaces calculated for proteins available in the PDB. Charges were calculated at pH 7.5 with PDB2PQR server http://nbcr-222.ucsd.edu/pdb2pqr_2.0.0/ using Amber force field and naming schemes. In blue, positive isosurfaces at + $10 \mathrm{kT} / \mathrm{e}^{-}$in red, negative isosurfaces at $-10 \mathrm{kT} / \mathrm{e}^{-}$. a Proteins triggering membrane proliferation when overproduced (monotopic MurG, PDB code 1FOK, [181] and transmembrane Fumarate reductase, PDB code 6AWF [1 19]); b proteins whose overproduction does not trigger membrane proliferation (MsbA, PDB code 6BPL [182, 183] and G3P transporter, PDB code 5XJ9 [184])

in "Mechanisms of protein-induced membrane curvature" section, all the proteins triggering inner membrane proliferation have the capacity to modify the membrane curvature and, hence, to induce CL clustering. Of note, this hypothesis can explain not only the production of inner membranes but also the enrichment in CL (instead of anionic PG that would be expected in the case of the electrostatic interactions hypothesis) observed in most examples of intracellular membrane proliferation upon protein overproduction. Furthermore, it could be the missing link to the ancestral mechanism of inner membrane compartments observed in $\alpha$-proteobacteria and mitochondria, where both the insertion of membrane curvature-inducing protein complexes and CL clustering are required.

\section{Influence of membrane curvature on phospholipid biosynthesis in eukaryotic cells}

Unicellular eukaryotes (especially yeasts) are, like prokaryotes, well-known hosts used for protein production and biotechnological applications. As in prokaryotes, intracellular membrane proliferation can also be induced by some membrane proteins overexpression in unicellular eukaryotes (mostly documented in S. cerevisiae and P. pastoris). To date, only transmembrane (not monotopic) proteins have been reported to trigger membrane proliferation in yeasts (Table 2). The first reports of membrane proliferation in eukaryotes described nuclear membrane structures (Karmellae), but since then, some have been shown to also originate from other cell organelles such as the endoplasmatic reticulum (ER), mitochondria, peroxisome or vacuole (Table 2). Membrane proliferation can now be specifically targeted to particular cellular organelles by engineering chimera proteins containing ad hoc signal peptides [151]. 


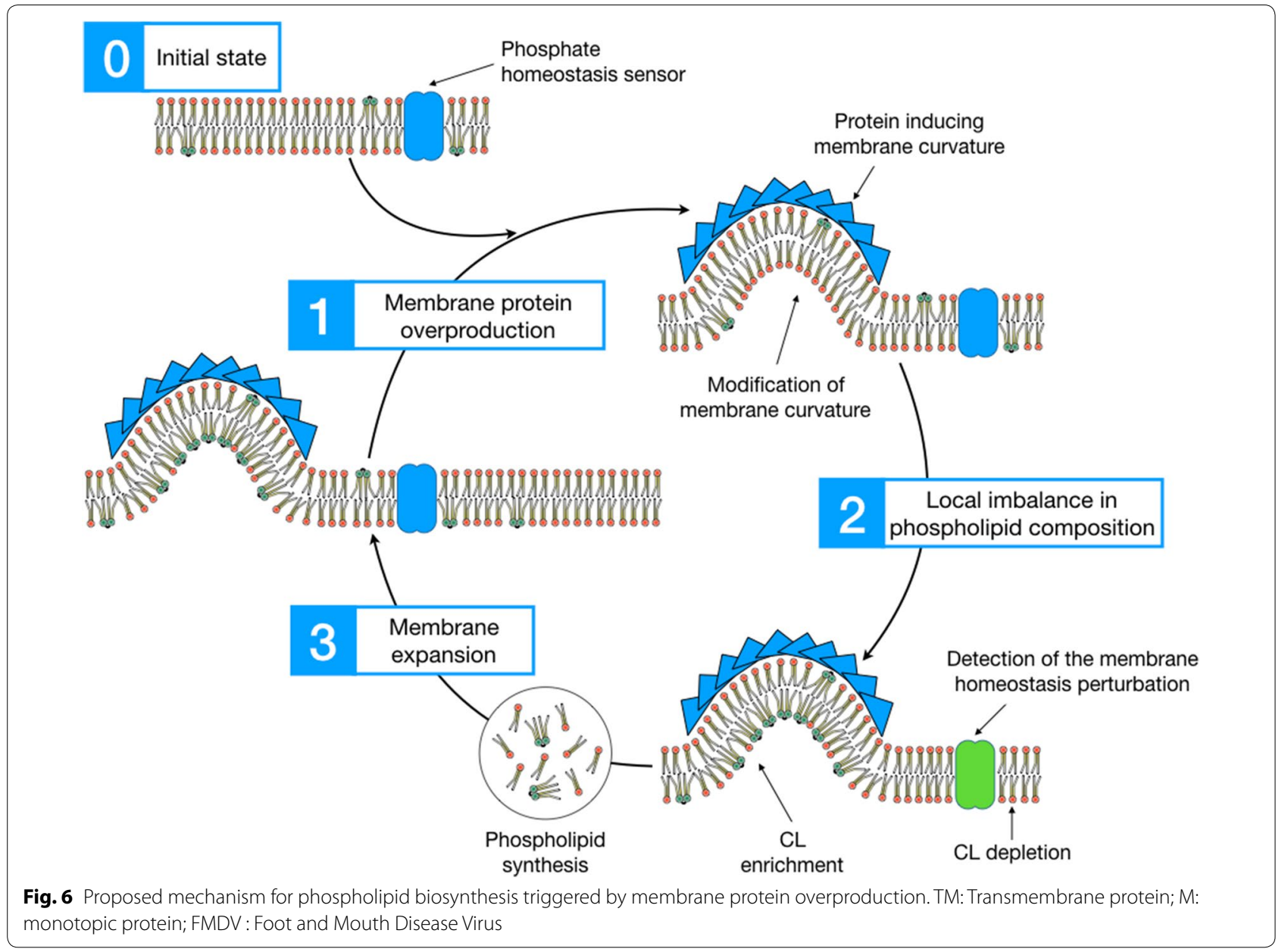

\section{The unfolded protein response}

The relationship between expression levels of recombinant membrane proteins and phospholipid biosynthesis has been studied more in depth in eukaryotes than in prokaryotes. Early reports on the activation of the inositol response pathway and the Unfolded Protein Response (UPR) in S.cerevisiae overproducing Hmg1 were the first attempts to link membrane proliferation to protein overproduction [194]. In yeast, UPR is controlled by Ire1, an integral ER membrane protein with an ER luminal domain sensitive to the presence of misfolded proteins (via the release of the chaperone Kar2, also known as $\mathrm{BiP})$ and a transmembrane and proximal domain sensing alterations of lipid composition in the ER membrane $[195,196]$. Either an accumulation of unfolded proteins or an imbalance of lipid homeostasis constitute lifethreatening events, which are tightly controlled by Ire1 (Fig. 7) [197]. Activation of Ire1 triggers the production of Hac1, a transcription factor that controls ca. 381 genes, including those of phospholipid biosynthesis, ERassociated protein degradation, protein translocation across ER membrane, vesicular trafficking, cell wall biogenesis, and vacuolar protein sorting [198]. It was then postulated that the overproduction of a membrane protein is a perturbation that could activate UPR response and, indirectly phospholipid biosynthesis through Ire1 sensor. Ire1 knock-out yeasts $(S$. cerevisiae $\Delta$ ire1) were constructed to test this hypothesis. However, membrane proliferation upon overproduction of P450 cytochrome or Pex15p was not impeded in $\Delta$ ire 1 yeasts $[199,200]$. Interestingly, $\Delta$ ire1 yeasts were still able to produce Kar2/BiP, which is a part of the UPR response. Thus, the authors postulated an alternative (and unknown) Ire1independent mechanism for UPR activation. Later, these observations were expanded to HMG-CoA reductase isozyme (Hmg1) overproduced in $\Delta$ ire 1 yeasts. In this case, membrane proliferation was achieved in complete independence from Ire1 and secretion of Kar2/Bip chaperone. Consequently, the authors concluded that, at least for Hmg1, membrane proliferation phenomena should be unrelated to UPR. However, the activation of UPR pathway seems somewhat advantageous for inner membrane 


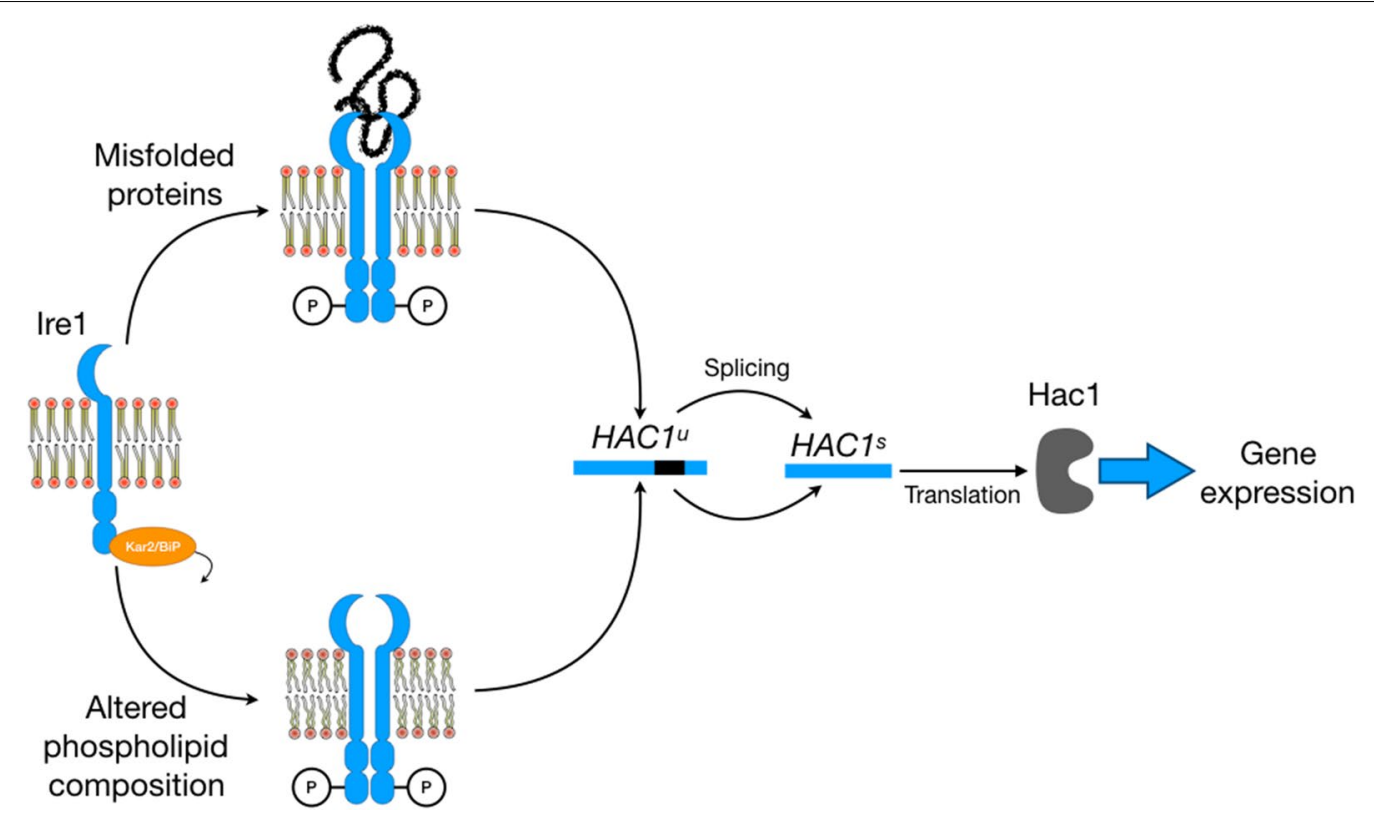

Fig. 7 UPR phospholipid sensor. Ire1 is able to detect the presence of misfolded proteins or alterations of phospholipid composition in the membrane of the ER and is activated by dimerization and autophosphorylation. This activation leads to an unconventional splicing of HAC1 mRNA and the translation of Hac1, which activates gene expression and phospholipid biosynthesis

proliferation, as the overproduction of the transcription factor Hac1 (the main product of UPR), using an external expression plasmid improved the production yield of membrane proteins and intracellular membranes [201, 202]. Interestingly, overproduction of Hac1 alone changes the morphology of the ER membrane to a cubic phase and increases the Kar2/BiP chaperon levels [201]. As previously discussed, bi-continuous cubic phase ER is often observed during the infection by + RNA viruses [89], which are known to induce membrane proliferation in both prokaryotes and eukaryotes. Additionally, stacks of Karmellae-like membranes surrounding the yeast nucleus are produced upon coexpression of Hac1 with a membrane protein, which alone would not trigger membrane proliferation [202].

\section{Inositol regulation pathway and the importance of phosphatidic acid}

How to reconciliate the fact that membrane proliferation in yeasts is at the same time influenced by and independent of UPR? A plausible explanation is the existence of redundant sensors capable of activating, independently

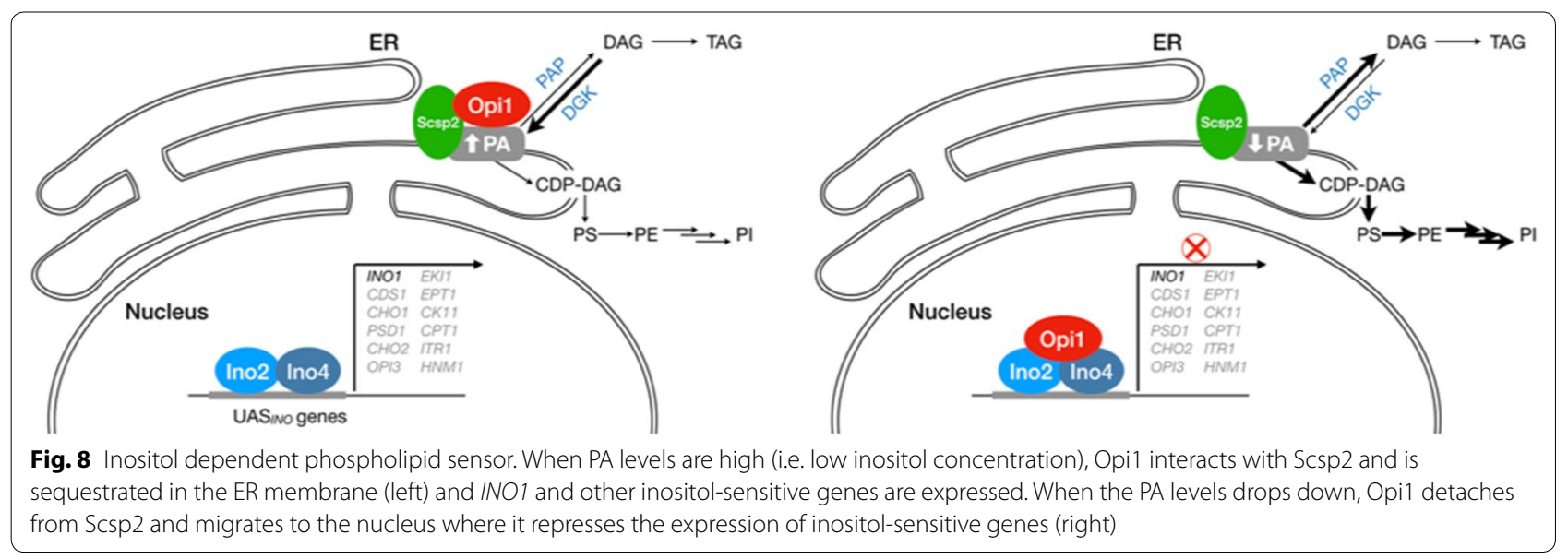


of UPR, the biosynthesis of phospholipids. PI and its precursor, inositol, are implicated in the inositol regulation pathway (INO1 genes), which is activated during membrane proliferation after canine $\mathrm{RRb}$ production in yeast cells [203]. INO1 promotes the synthesis of phospholipids (and many other inositol-sensitive genes) and is regulated independently of UPR by the couple of activators Ino2/ Ino4 and repressed by Opi1 (Fig. 8) [204]. This regulation system is clearly related to membrane proliferation, as mutants deficient of Ino2 failed to produce intracellular membranes upon $\mathrm{RRb}$ expression, whereas deletion of the repressor Opi1 favors the proliferation of inner membranes [203]. All the genes under inositol regulation (including INO1) are, in fact, controlled by phosphatidic acid (PA) levels, which is a central regulator of both the synthesis of phospholipids and reserve lipids (triacylglycerides) in S. cerevisiae [205]. Opi1 is a soluble protein associated to a transmembrane protein (Scs2), which acts as a membrane sensor for PA microdomains [206, 207]. When PA concentration is sufficient, Opi1 remains inactive and anchored to Scs2 in the ER membrane. On the contrary, when PA concentration drops down, Opi1 is released and imported to the nucleus where it represses the phospholipid synthesis.

\section{Other regulatory mechanisms}

In addition, the regulation of phospholipid homeostasis in S. cerevisiae is controlled by multiple biochemical and genetic factors and goes well beyond UPR and inositol regulation pathways [208]. Therefore, the existence of additional regulatory pathways to control phospholipid biosynthesis upon protein overproduction cannot be ruled out. In fact, intracellular membrane proliferation of ER in S. cerevisiae is associated with altered membrane trafficking. For example, overproduction of Sec12p blocks the ER-to-Golgi intracellular trafficking of S.cerevisiae and induces the formation of clusters of the chaperone Kar2/BiP, like in UPR pathway [209]. Similar blockage of intracellular trafficking was also observed after overexpression of the poliovirus $2 \mathrm{BC}$ protein and the peroxisomal Pex15p protein, which both accumulate newly formed ER membranes [99, 210]. Conversely, the overproduction of the canine RRp enhances the secretory pathways in S. cerevisiae [130]. Of note, this altered intracellular trafficking is not a general scenario for all the protein-induced intracellular membrane proliferation in eukaryotes, as exemplified with Hmg1 [209]. It is not clear whether these alterations of cellular trafficking are only a consequence of membrane proliferation or, on the contrary, contribute to inner membrane proliferation in eukaryotes. In any case, regardless of the precise mechanism, the biosynthesis of phospholipids also seems to be controlled by the membrane composition in eukaryotes.

\section{Cardiolipin and phosphatidic acid membrane microdomains: a universal regulator mechanism for phospholipid biosynthesis conserved through evolution?}

PA seems to be a central actor in phospholipid biosynthesis regulation in eukaryotes [208]. For instance, increased PA cellular levels, either by a lack of PA degradation due to lower PA phosphatase activity or by an increase in PA concentration due to an overproduction of diacylglycerol kinases, leads to an expansion of the nuclear membrane [211-213]. It should be noted that this membrane expansion in the absence of any membrane protein modulating membrane curvature leads to yeasts with an aberrantly large nucleus, without any organized membrane morphology (e.g. stacks of membranes, tubules or vesicles). Furthermore, PA and CL also play a central role in the regulation of membrane dynamics (fusion and division) in mitochondria [214].

From a physicochemical point of view, the phospholipids found at the core of membrane proliferation in eukaryotes and prokaryotes (PA and CL), are strikingly similar (Fig. 9) [215]. Both PA and CL are cone-shaped anionic phospholipids that accumulate in zones of negative curvature in biological membranes. Furthermore, both of them have two ionizable positions (Fig. 9), determined by two distinct $\mathrm{pK}_{\mathrm{a}}$ values $[216,217]$. Their exact values and hence, the ionization state of PA and CL, depend on the membrane local environment. Indeed, different ionization states of PA controlled by lipid-protein interactions have been proposed to explain the regulatory role of PA in eukaryotes [216]. Similarly, CL undergoes changes in lipid packing as a function of its environment, external $\mathrm{pH}$ and divalent cations $[218,219]$.

As discussed before, proteins inducing membrane proliferation in both prokaryotic and eukaryotic cells are characterized by their ability to bend the membrane. At the same time, cone-shaped anionic PA and CL share a marked preference for negatively curved regions of the membrane. Therefore, the disturbance of phospholipid homeostasis via the creation of membrane microdomains enriched in PA or CL might be a central regulator of phospholipid metabolism conserved through evolution.

\section{Conclusions and perspectives}

Despite the variety of inducible membranes and host cells reported in the literature, the proteins triggering membrane proliferation share some common properties. They are able to modify membrane curvature and 


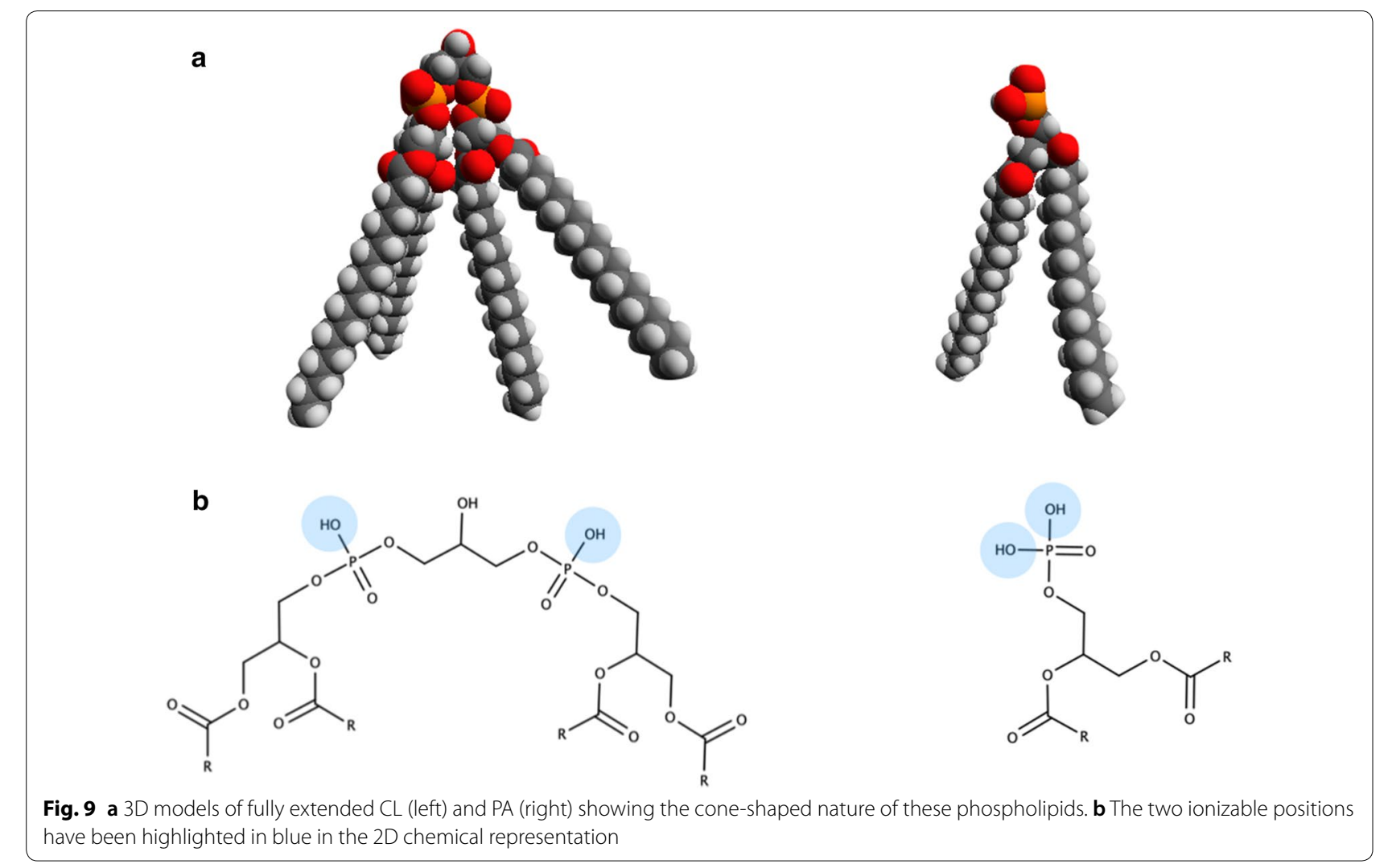

hijack the regulation of phospholipid synthesis, where anionic, non-bilayer-forming phospholipids (CL and PA) seem to play a central role. We reviewed the mechanisms involved in phospholipid homeostasis, identifying their possible coordination with membrane protein biosynthesis. The hypothesis that phospholipid production might be induced by electrostatic interactions between anionic phospholipids and a positively charged lobe of the protein has been ruled out. Taking into account all the reviewed information, we propose a general mechanism of intracellular membrane proliferation in which the overproduced recombinant proteins can induce high curvature local areas, creating clusters of anionic, cone-shaped phospholipids (CL in prokaryotes and PA in eukaryotes). The accumulation of these phospholipids in the curved microdomains causes a phospholipid imbalance in the non-curved areas of the cell membrane. This local imbalance is likely to be detected by the phosphate homeostasis sensors, which in turn, will stimulate phospholipid biosynthesis. Upon the continuous accumulation of the recombinant protein (or their supramolecular assemblies), new curved microdomains are produced, and the cell is forced to constantly synthesize new phospholipids to maintain phospholipid homeostasis. The final consequence is an expansion of the intracellular membranes displaying the different morphologies observed in cellulo.
This general mechanism of intracellular membrane proliferation shares common features with the formation of energetic compartments in $\alpha$-proteobacteria (and mitochondria), and for some viruses, which remodel the inner membrane structures of the host to create their replication organelles. In both cases, the membrane expansion is triggered by the insertion of proteins that modulate membrane curvature, causing the accumulation of nonbilayer forming lipids (CL or PA). In summary, the modification of membrane curvature can act in cellulo as an inducer of phospholipid biosynthesis and membrane expansion and it is probably a conserved feature through evolution.

\section{Abbreviations}

alMGS: monoglucosyldiacylglycerol synthase; alphaMic60: a-proteobacteria Mic60 analogue; BAR: Bin Amhiphysin Rvs; BDLP: bacterial dynamin like proteins; $B_{2}$ receptor: Human Bradykinin subtype 2 receptor; $C L$ : cardiolipin; CMP: cytosine monophosphate; CTP: cytosine triphosphate; DivIVA: cell division protein IVA; $D_{2 S}$ receptor: dopamine receptor type $2 \mathrm{~s}$; ENTH: Epsin $\mathrm{NH}_{2}$-Terminal Homology; FisB: fission protein B; FMDV: foot and mouth disease virus; FtsA/K/Z: filamentous temperature sensitive protein A/KVZ; Kar2: endoplasmic reticulum chaperone BiP; G3P: glycerol-3-phosphate; Hac1: homologous to Atf/Creb1; Hmg-CoA: 3-hydroxy-3- methylglutaryl coenzyme $\mathrm{A}$; Hmg1: isozyme 1 of $\mathrm{Hmg}-\mathrm{CoA}$; INO: inositol regulated genes; Ire1: serine/threonine-protein kinase/endoribonuclease; LH: light harvesting complex; LpxB: lipid-A-disaccharide synthase; mam: magnetosome membrane-associated; MDO: membrane derived oligosaccharides; Mic60: subunit Mic60 of mitochondrial contact site and cristae organizing system 
complex; MurG: UDP-N-acetylglucosamine- $N$-acetylmuramyl-(pentapeptide) pyrophosphoryl-undecaprenol $\mathrm{N}$-acetylglucosamine transferase; MsbA: lipid A export ATP-binding/permease protein MsbA; NOc: nucleoid occlusion; Opi1: transcriptional repressor OPI1; PA: phosphatidic acid; PE: phosphatidylethanolamine; Pex12p: peroxisome assembly protein 12; Pex15p: peroxisomal membrane protein 15; PG: phosphatidylglycerol; PI: phosphatidylinositol; PI4P: phosphatidylinositol-4-phosphate; PMA2: plasma membrane H+-ATPase 2; PmtA: phospholipid N-methyltransferase A; PgsA: CDP-diacylglycerol-glycerol3-phosphate 3-phosphatidyltransferase; PssA: phosphatidylserine synthase; PufX: intrinsic membrane protein PufX; RC: reaction center; +RNA: positivesense single stranded RNA; RRp: canine ribosome receptor; Scs2: membrane protein-associated SCS2; Sec12p: guanine nucleotide-exchange factor SEC12; Sk2 channel: small conductance Ca2+-activated K+ channel ; SpollIDMP: stage II sporulation proteins D, M and P complex; SpolllE: stage III sporulation protein $E_{;}$SpoVM: stage $V$ sporulation protein $M$; Tsr: serine chemotaxis receptor; UPR: unfolded protein response; ZipA: cell division protein ZipA.

\section{Acknowledgements}

We acknowledge CNRS, INSERM and Ecole Normale Supérieure.

\section{Authors' contributions}

All authors contributed to manuscript design and content. JR overall coordinated all the manuscript parts, designed the tables and figures and organized the literature. VB contribution was essential for "Electrostatic interactions between anionic phospholipids and positively charged proteins" and "Formation of $\mathrm{CL}$ microdomains" sections and Fig. 5. ND reviewed the physiological membrane remodeling processes in "Influence of membrane curvature in membrane remodeling" and "Evolutive origin of intracellular organelles" sections. CT provided insights in the biotechnological applications and contributed to the physico-chemical discussion. BM contributed to the discussion of membrane protein overproduction. All authors read and approved the final manuscript.

\section{Funding}

'Initiative d'Excellence' program from the French State (Grant 'DYNAMO', ANR11-LABEX-0011-01) and from the ANR GeneCap (ANR-17-CE09-0007).

\section{Availability of data and materials}

Not applicable.

\section{Ethics approval and consent to participate}

Not applicable.

\section{Consent for publication}

Not applicable.

\section{Competing interests}

The authors declare that they have no competing interests.

\section{Author details}

${ }^{1}$ Laboratoire de Biologie Physico-Chimique des Protéines Membranaires, Université de Paris, LBPC-PM, CNRS, UMR7099, 75005 Paris, France. ${ }^{2}$ Institut de Biologie Physico-Chimique, Fondation Edmond de Rothschild pour le Développement de la Recherche Scientifique, 75005 Paris, France. ${ }^{3}$ Département de Chimie, École Normale Supérieure, PASTEUR, PSL University, CNRS, Sorbonne Université, 24 Rue Lhomond, 75005 Paris, France.

Received: 20 April 2020 Accepted: 27 August 2020

Published online: 04 September 2020

\section{References}

1. Hollinshead W, He L, Tang YJ. Biofuel production: an odyssey from metabolic engineering to fermentation scale-up. Front Microbiol. 2014;5:1-8.

2. Zhou YJ, Buijs NA, Zhu Z, Qin J, Siewers V, Nielsen J. Production of fatty acid-derived oleochemicals and biofuels by synthetic yeast cell factories. Nat Commun. 2016;7:11709.

3. Myhrvold C, Polka JK, Silver PA. Synthetic lipid-containing scaffolds enhance production by colocalizing enzymes. ACS Synth Biol. 2016;5:1396-403.
4. Zoonens M, Miroux B. Expression of membrane proteins at the Escherichia coli membrane for structural studies. In: Mus-Veteau I, editor. Heterologous expression membrane proteins methods protocol. Totowa: Humana Press; 2010. p. 49-66.

5. Dilworth MV, Piel MS, Bettaney KE, Ma P, Luo J, Sharples D, et al. Microbial expression systems for membrane proteins. Methods. 2018;147:3-39.

6. Miroux B, Walker JE. Over-production of proteins in Escherichia coli: Mutant hosts that allow synthesis of some membrane proteins and globular proteins at high levels. J Mol Biol. 1996;260:289-98.

7. Baumgarten T, Schlegel S, Wagner S, Löw M, Eriksson J, Bonde I, et al. Isolation and characterization of the E. coli membrane protein production strain Mutant56(DE3). Sci Rep. 2017;7:1-14.

8. Angius F, llioaia O, Amrani A, Suisse A, Rosset L, Legrand A, et al. A novel regulation mechanism of the T7 RNA polymerase based expression system improves overproduction and folding of membrane proteins. Sci Rep. 2018;8:1-11.

9. Pichler $\mathrm{H}$, Emmerstorfer-Augustin A. Modification of membrane lipid compositions in single-celled organisms - From basics to applications. Methods. 2018;147:50-65.

10. Kanonenberg K, Royes J, Kedrov A, Poschmann G, Angius F, Solgadi A, et al. Shaping the lipid composition of bacterial membranes for membrane protein production. Microb Cell Fact. 2019;18:131.

11. Jung $Y$, Jung $H$, Lim D. Bacteriophage membrane protein $P 9$ as a fusion partner for the efficient expression of membrane proteins in Escherichia coli. Protein Expr Purif. 2015;116:12-8.

12. Fais S, O'Driscoll L, Borras FE, Buzas E, Camussi G, Cappello F, et al. Evidence-based clinical use of nanoscale extracellular vesicles in nanomedicine. ACS Nano. 2016;10:3886-99.

13. Raposo G, Stahl PD. Extracellular vesicles: a new communication paradigm? Nat Rev Mol Cell Biol. 2019;20:509-10.

14. Kulp A, Kuehn MJ. Biological functions and biogenesis of secreted bacterial outer membrane vesicles. Annu Rev Microbiol. 2010;64:163-84.

15. Busatto S, Zendrini A, Radeghieri A, Paolini L, Romano M, Presta M, et al. The nanostructured secretome. Biomater Sci R Soc Chem. 2020;8:39-63.

16. Kim OY, Choi SJ, Jang SC, Park KS, Kim SR, Choi JP, et al. Bacterial protoplast-derived nanovesicles as vaccine delivery system against bacterial infection. Nano Lett. 2015;15:266-74.

17. Kim OY, Dinh NTH, Park HT, Choi SJ, Hong K, Gho YS. Bacterial protoplast-derived nanovesicles for tumor targeted delivery of chemotherapeutics. Biomaterials. 2017;113:68-79.

18. Yuan J, Yang J, Hu Z, Yang Y, Shang W, Hu Q, et al. Safe staphylococcal platform for the development of multivalent nanoscale vesicles against viral infections. Nano Lett. 2018;18:725-33.

19. Yang LM, Zheng H, Ratnakar JS, Adebesin BY, Do QN, Kovacs Z, et al. Engineering a pH-sensitive liposomal MRI agent by modification of a bacterial channel. Small. 2018;14:1-9.

20. Royes J, llioaia O, Lubart Q, Angius F, Dubacheva GV, Bally M, et al. Bacteria-based production of thiol-clickable, genetically encoded lipid nanovesicles. Angew Chemie Int Ed. 2019;58:7395-9.

21. Gerritzen MJH, Martens DE, Wijffels RH, van der Pol L, Stork M. Bioengineering bacterial outer membrane vesicles as vaccine platform. Biotechnol Adv. 2017:35:565-74

22. Farjadian F, Moghoofei M, Mirkiani S, Ghasemi A, Rabiee N, Hadifar S, et al. Bacterial components as naturally inspired nano-carriers for drug/ gene delivery and immunization: Set the bugs to work? Biotechnol Adv. 2018;36:968-85.

23. Vega-Cabrera LA, Pardo-López L. Membrane remodeling and organization: Elements common to prokaryotes and eukaryotes. IUBMB Life. 2017;69:55-62.

24. Zimmerberg J, Kozlov MM. How proteins produce cellular membrane curvature. Nat Rev Mol Cell Biol. 2005;7:9.

25. Nishimura T, Morone N, Suetsugu S. Membrane re-modelling by BAR domain superfamily proteins via molecular and non-molecular factors. Biochem Soc Trans. 2018;46:379-89.

26. Zhao H, Michelot A, Koskela EV, Tkach V, Stamou D, Drubin DG, et al. Membrane-Sculpting BAR domains generate stable lipid microdomains. Cell Rep. 2013;4:1213-23.

27. Phillips DA, Zacharoff LA, Hampton CM, Chong GW, Malanoski P, Metskas $L A$, et al. A prokaryotic membrane sculpting BAR domain protein. bioRxiv. 2020;1:32. 
28. Tanaka M, Arakaki A, Matsunaga T. Identification and functional characterization of liposome tubulation protein from magnetotactic bacteria. Mol Microbiol. 2010;76:480-8.

29. Jimah JR, Hinshaw JE. Structural insights into the mechanism of dynamin superfamily proteins. Trends Cell Biol. 2019;29:257-73.

30. Bramkamp M. Structure and function of bacterial dynamin-like proteins. Biol Chem. 2012;393:1203-14.

31. Schlimpert S, Wasserstrom S, Chandra G, Bibb MJ, Findlay KC, Flärdh K, et al. Two dynamin-like proteins stabilize FtsZ rings during Streptomyces sporulation. Proc Natl Acad Sci USA. 2017;114:E6176-83.

32. Bürmann F, Ebert N, Van Baarle S, Bramkamp M. A bacterial dynaminlike protein mediating nucleotide-independent membrane fusion. Mol Microbiol. 2011;79:1294-304.

33. Sawant $P$, Eissenberger $K$, Karier $L$, Mascher T, Bramkamp M. A dynaminlike protein involved in bacterial cell membrane surveillance under environmental stress. Environ Microbiol. 2016;18:2705-20.

34. Guo L, Bramkamp M. Bacterial dynamin-like protein DynA mediates lipid and content mixing. FASEB J. 2019;33:11746-57.

35. Wang H, Zhang C, Xiao H. Mechanism of membrane fusion: proteinprotein interaction and beyond. Int J Physiol Pathophysiol Pharmacol. 2019;11:250-7.

36. Michie KA, Boysen A, Low HH, Møller-Jensen J, Löwe J. LeoA, B and C from Enterotoxigenic Escherichia coli (ETEC) are bacterial dynamins. PLOS ONE. 2014;9:9.

37. Mileykovskaya E, Dowhan W. Role of membrane lipids in bacterial division-site selection. Curr Opin Microbiol. 2005;8:135-42.

38. Barák I, Muchová K. The role of lipid domains in bacterial cell processes. Int J Mol Sci. 2013;14:4050-65.

39. Kretschmer S, Ganzinger KA, Franquelim HG, Schwille P. Synthetic cell division via membrane-transforming molecular assemblies. BMC Biol. 2019:17:1-10

40. den Blaauwen T, Hamoen LW, Levin PA. The divisome at 25: the road ahead. Curr Opin Microbiol 2017;36:85-94.

41. Conti J, Viola MG, Camberg JL. FtsA reshapes membrane architecture and remodels the Z-ring in Escherichia coli. Mol Microbiol. 2018;107:558-76.

42. Krupka M, Cabré EJ, Jiménez M, Rivas G, Rico Al, Vicente M. Role of the Fts A C terminus as a switch for polymerization and membrane association. MBio. 2014;5:1-9.

43. Snead WT, Hayden CC, Gadok AK, Zhao C, Lafer EM, Rangamani P, et al. Membrane fission by protein crowding. Proc Natl Acad Sci USA. 2017;114:E3258-67.

44. Steinkühler J, Knorr RL, Zhao Z, Bhatia T, Bartelt SM, Wegner S, et al. Controlled division of cell-sized vesicles by low densities of membranebound proteins. Nat Commun. 2020;11:905.

45. Osawa M, Erickson HP. Liposome division by a simple bacterial division machinery. Proc Natl Acad Sci USA. 2013;110:11000-4.

46. Fleming TC, Shin JY, Lee SH, Becker E, Huang KC, Bustamante C, et al. Dynamic SpollIE assembly mediates septal membrane fission during Bacillus subtilis sporulation. Genes Dev. 2010;24:1160-72.

47. Liu NJL, Dutton RJ, Pogliano K. Evidence that the SpollIE DNA translocase participates in membrane fusion during cytokinesis and engulfment. Mol Microbiol. 2006:59:1097-113.

48. Meyer P, Gutierrez J, Pogliano K, Dworkin J. Cell wall synthesis is necessary for membrane dynamics during sporulation of Bacillus subtilis. Mol Microbiol. 2010;76:956-70.

49. Khanna K, Lopez-Garrido J, Zhao Z, Watanabe R, Yuan Y, Sugie J, et al. The molecular architecture of engulfment during Bacillus subtilis sporulation. Elife. 2019;8:1-22.

50. Broder DH, Pogliano K. Forespore engulfment mediated by a ratchetlike mechanism. Cell. 2006;126:917-28.

51. Doan T, Coleman J, Marquis KA, Meeske AJ, Burton BM, Karatekin E, et al. FisB mediates membrane fission during sporulation in bacillus subtilis. Genes Dev. 2013;27:322-34.

52. Pedrido ME, de Oña P, Ramirez W, Leñini C, Goñi A, Grau R. Spo0A links de novo fatty acid synthesis to sporulation and biofilm development in Bacillus subtilis. Mol Microbiol. 2013;87:348-67.

53. Kawai F, Shoda M, Harashima R, Sadaie Y, Hara H, Matsumoto K. Cardiolipin domains in Bacillus subtilis Marburg membranes. J Bacteriol. 2004;186:1475-83.
54. Kawai F, Hara H, Takamatsu H, Watabe K, Matsumoto K. Cardiolipin enrichment in spore membranes and its involvement in germination of Bacillus subtilis Marburg. Genes Genet Syst. 2006;81:69-76.

55. Ramamurthi KS, Lecuyer S, Stone HA, Losick R. Geometric cue for protein localization in a bacterium. Science. 2009;323:1354-7.

56. Gill RL, Castaing JP, Hsin J, Tan IS, Wang X, Huang KC, et al. Structural basis for the geometry-driven localization of a small protein. Proc Natl Acad Sci U S A. 2015;112:E1908-15.

57. Gupta RS. The phylogeny of proteobacteria: Relationships to other eubacterial phyla and eukaryotes. FEMS Microbiol Rev. 2000;24:367-402.

58. Muñoz-Gómez SA, Wideman JG, Roger AJ, Slamovits CH, Agashe D. The origin of mitochondrial cristae from alphaproteobacteria. Mol Biol Evol. 2017:34:943-56.

59. Muñoz-Gómez SA, Slamovits CH, Dacks JB, Baier KA, Spencer KD, Wideman JG. Ancient homology of the mitochondrial contact site and cristae organizing system points to an endosymbiotic origin of mitochondrial cristae. Curr Biol. 2015;25:1489-95.

60. Woronowicz K, Harrold JW, Kay JM, Niederman RA. Structural and functional proteomics of intracytoplasmic membrane assembly in Rhodobacter sphaeroides. J Mol Microbiol Biotechnol. 2013;23:48-62.

61. Horvath SE, Rampelt H, Oeljeklaus S, Warscheid B, Van Der Laan M, Pfanner N. Role of membrane contact sites in protein import into mitochondria. Protein Sci. 2015;24:277-97.

62. Niederman RA. Development and dynamics of the photosynthetic apparatus in purple phototrophic bacteria. Biochim Biophys Acta Bioenerg. 2016;1857:232-46.

63. Huynen MA, Mühlmeister M, Gotthardt K, Guerrero-Castillo S, Brandt $U$. Evolution and structural organization of the mitochondrial contact site (MICOS) complex and the mitochondrial intermembrane space bridging (MIB) complex. Biochim Biophys Acta - Mol Cell Res. 2016;1863:91-101.

64. Tarasenko D, Barbot M, Jans DC, Kroppen B, Sadowski B, Heim G, et al. The MICOS component Mic60 displays a conserved membrane-bending activity that is necessary for normal cristae morphology. J Cell Biol. 2017;216:889-99.

65. Tian HF, Feng JM, Wen JF. The evolution of cardiolipin biosynthesis and maturation pathways and its implications for the evolution of eukaryotes. BMC Evol Biol. 2012;1:2.

66. Mileykovskaya E, Dowhan W. Cardiolipin membrane domains in prokaryotes and eukaryotes. Biochim Biophys Acta - Biomembr. 2009;1788:2084-91.

67. Paradies G, Paradies V, Ruggiero FM, Petrosillo G. Role of cardiolipin in mitochondrial function and dynamics in health and disease: molecular and pharmacological aspects. Cells. 2019;8:728.

68. Matsumura A, Higuchi J, Watanabe Y, Kato M, Aoki K, Akabane S, et al. Inactivation of cardiolipin synthase triggers changes in mitochondrial morphology. FEBS Lett. 2018;592:209-18.

69. Kojima R, Kakimoto Y, Furuta S, Itoh K, Sesaki H, Endo T, et al. Maintenance of cardiolipin and crista structure requires cooperative functions of mitochondrial dynamics and phospholipid transport. Cell Rep 2019;26:518-28.e6.

70. Barber-Zucker S, Zarivach R. A look into the biochemistry of Magnetosome biosynthesis in magnetotactic bacteria. ACS Chem Biol. 2017:12:13-22.

71. Murat D, Quinlan A, Vali H, Komeili A. Comprehensive genetic dissection of the magnetosome gene island reveals the step-wise assembly of a prokaryotic organelle. Proc Natl Acad Sci USA. 2010;107:5593-8.

72. Raschdorf O, Forstner Y, Kolinko I, Uebe R, Plitzko JM, Schüler D. Genetic and ultrastructural analysis reveals the key players and initial steps of bacterial magnetosome membrane biogenesis. PLoS Genet. 2016;12:1-23.

73. Komeili A. Molecular mechanisms of compartmentalization and biomineralization in magnetotactic bacteria. FEMS Microbiol Rev. 2012;36:232-55.

74. Barber-Zucker S, Keren-Khadmy N, Zarivach R. From invagination to navigation: The story of magnetosome-associated proteins in magnetotactic bacteria. Protein Sci. 2016;25:338-51.

75. Tanaka M, SuwatthanarakT, Arakaki A, Johnson BRG, Evans SD, Okochi $M$, et al. Enhanced tubulation of liposome containing cardiolipin 
by mamy protein from magnetotactic bacteria. Biotechnol $\mathrm{J}$. 2018;13:1800087.

76. Toro-Nahuelpan M, Zagoriy I, Senger F, et al. Tailoring cryo-electron microscopy grids by photo-micropatterning for in-cell structural studies. Nat Methods 2020;17:50-4. https://doi.org/10.1038/s4159 2-019-0630-5

77. Hsin J, Gumbart J, Trabuco LG, Villa E, Qian P, Hunter CN, et al. Proteininduced membrane curvature investigated through molecular dynamics flexible fitting. Biophys J. 2009;97:321-9.

78. Qian P, Bullough PA, Hunter CN. Three-dimensional reconstruction of a membrane-bending complex: The RC-LH1-PufX core dimer of rhodobacter sphaeroides. J Biol Chem. 2008;283:14002-11.

79. Tucker JD, Siebert CA, Escalante M, Adams PG, Olsen JD, Otto C, et al. Membrane invagination in Rhodobacter sphaeroides is initiated at curved regions of the cytoplasmic membrane, then forms both budded and fully detached spherical vesicles. Mol Microbiol. 2010;76:833-47.

80. Chandler DE, Hsin J, Harrison CB, Gumbart J, Schulten K. Intrinsic curvature properties of photosynthetic proteins in chromatophores. Biophys J. 2008;95:2822-36.

81. Chandler DE, Gumbart J, Stack JD, Chipot C, Schulten K. Membrane curvature induced by aggregates of $\mathrm{LH} 2 \mathrm{~s}$ and monomeric $\mathrm{LH} 1 \mathrm{~s}$. Biophys J Biophysical Society. 2009;97:2978-84.

82. Scheuring S, Nevo R, Liu LN, Mangenot S, Charuvi D, Boudier T, et al. The architecture of Rhodobacter sphaeroides chromatophores. Biochim Biophys Acta - Bioenerg. 2014;1837:1263-70.

83. Romero-Brey I, Bartenschlager R. Endoplasmic reticulum: The favorite intracellular niche for viral replication and assembly. Viruses. 2016:8:1-26.

84. Harak C, Lohmann V. Ultrastructure of the replication sites of positivestrand RNA viruses. Virology. 2015;479-480:418-33.

85. Shulla A, Randall G. (+) RNA virus replication compartments: A safe home for (most) viral replication. Curr Opin Microbiol 2016;32:82-8.

86. Welsch S, Miller S, Romero-Brey I, Merz A, Bleck CKE, Walther P, et al. Composition and three-dimensional architecture of the dengue virus replication and assembly sites. Cell Host Microbe. 2009;5:365-75.

87. Gillespie LK, Hoenen A, Morgan G, Mackenzie JM. The endoplasmic reticulum provides the membrane platform for biogenesis of the flavivirus replication complex. J Virol. 2010;84:10438-47.

88. Miller S, Krijnse-Locker J. Modification of intracellular membrane structures for virus replication. Nat Rev Microbiol. 2008;6:363-74.

89. van der Schaar HM, Dorobantu CM, Albulescu L, Strating JRPM, van Kuppeveld FJM. Fat(al) attraction: picornaviruses usurp lipid transfer at membrane contact sites to create replication organelles. Trends Microbiol. 2016;24:535-46.

90. Altan-Bonnet N. Lipid tales of viral replication and transmission. Trends Cell Biol. 2017;27:201-13.

91. Zhang Z, He G, Filipowicz NA, Randall G, Belov GA, Kopek BG, et al. Host lipids in positive-strand RNA virus genome replication. Front Microbiol. 2019;10:1-18.

92. Weisberg AS, Maruri-Avidal L, Bisht H, Hansen BT, Schwartz CL, Fischer $E R$, et al. Enigmatic origin of the poxvirus membrane from the endoplasmic reticulum shown by $3 \mathrm{D}$ imaging of vaccinia virus assembly mutants. Proc Natl Acad Sci U S A. 2017;114:E11001-9.

93. Moss B. Origin of the poxviral membrane: A 50-year-old riddle. PLoS Pathog. 2018;14:1-6.

94. Koonin EV, Dolja WV, Krupovic M. Origins and evolution of viruses of eukaryotes: The ultimate modularity. Virology. 2015;479-480:2-25.

95. McGraw T, Mindich L, Frangione B. Nucleotide sequence of the small double-stranded RNA segment of bacteriophage $\varphi 6$ : Novel mechanism of natural translational control. J Virol. 1986;58:142-51.

96. Weiner JH, Lemire BD, Elmes ML, Bradley RD, Scraba DG. Overproduction of fumarate reductase in Escherichia coli induces a novel intracellular lipid-protein organelle. J Bacteriol. 1984;158:590-6.

97. Weber S, Granzow H, Weiland F, Marquardt O. Intracellular membrane proliferation in E-coli induced by foot-and-mouth disease virus $3 \mathrm{~A}$ gene products. Virus Genes. 1996;12:5-14.

98. Wright R, Basson M, D'Ari L, Rine J. Increased amounts of HMG-CoA reductase induce "karmellae": A proliferation of stacked membrane pairs surrounding the yeast nucleus. J Cell Biol. 1988;107:101-14.
99. Barco A, Carrasco L. A human virus protein, poliovirus protein 2BC, induces membrane proliferation and blocks the exocytic pathway in the yeast Saccharomyces cerevisiae. EMBO J. 1995;14:3349-64.

100. Arechaga I. Membrane invaginations in bacteria and mitochondria: common features and evolutionary scenarios. J Mol Microbiol Biotechnol. 2013;23:13-23.

101. Jamin N, Garrigos M, Jaxel C, Frelet-Barrand A, Orlowski S. Ectopic neo-formed intracellular membranes in Escherichia coli: A response to membrane protein-induced stress involving membrane curvature and domains. Biomolecules. 2018;8:88.

102. Simunovic M, Evergren E, Golushko I, Prévost C, Renard H-F, Johannes L, et al. How curvature-generating proteins build scaffolds on membrane nanotubes. Proc Natl Acad Sci USA 2016;113:11226-31.

103. Parton RG. Caveolae. Structure, Function, and Relationship to Disease. Annu Rev Cell Dev Biol. 2018;34:111-36.

104. Walser PJ, Ariotti N, Howes M, Ferguson C, Webb R, Schwudke $D$, et al. Constitutive formation of caveolae in a bacterium. Cell. 2012;150:752-63.

105. Ariotti N, Rae J, Leneva N, Ferguson C, Loo D, Okano S, et al. Molecular characterization of caveolin-induced membrane curvature. J Biol Chem. 2015;290:24875-90.

106. Männistö RH, Kivelä HM, Paulin L, Bamford DH, Bamford JKH. The complete genome sequence of $\mathrm{PM} 2$, the first lipid-containing bacterial virus to be isolated. Virology. 1999;262:355-63.

107. Abrescia NGA, Grimes JM, Kivelä HM, Assenberg R, Sutton GC, Butcher $\mathrm{SJ}$, et al. Insights into virus evolution and membrane biogenesis from the structure of the marine lipid-containing bacteriophage PM2. Mol Cell. 2008;31:749-61.

108. Armour GA, Brewer JG. Membrane morphogenesis from cloned fragments of bacteriophage PM2 DNA that contain the sp6.6 gene. FASEB J. 1990:4:1488-93.

109. Breese SS, Graves JH. Electron microscopic observation of crystalline arrays of foot-and-mouth disease virus. J Bacteriol. 1966;92:1835-7.

110. Deng Y, Almsherqi ZA, Ng MML, Kohlwein SD. Do viruses subvert cholesterol homeostasis to induce host cubic membranes? Trends Cell Biol. 2010;20:371-9.

111. González-Magaldi M, Martín-Acebes MA, Kremer L, Sobrino F. Membrane topology and cellular dynamics of foot-and-mouth disease virus 3A protein. PLOS ONE. 2014;9:1-12.

112. Johnson MD, Mindich L. Plasmid-directed assembly of the lipid-containing membrane of bacteriophage $\varphi 6$. J Bacteriol. 1994;176:4124-32.

113. Sarin LP, Hirvonen JJ, Laurinmaki P, Butcher SJ, Bamford DH, Poranen MM. Bacteriophage 6 nucleocapsid surface protein 8 interacts with virus-specific membrane vesicles containing major envelope protein 9. J Virol. 2012;86:5376-9.

114. Lyytinen OL, Starkova D, Poranen MM. Microbial production of lipidprotein vesicles using enveloped bacteriophage phi6. Microb Cell Fact. 2019;18:1-9.

115. Mindich L, Sinclair JF, Cohen J. The morphogenesis of bacteriophage phi6: Particles formed by nonsense mutants. Virology. 1976;75:224-31.

116. Elmes ML, Scraba DG, Weiner JH. Isolation and characterization of the tubular organelles induced by fumarate reductase overproduction in Escherichia coli. J Gen Microbiol. 1986;132:1429-39.

117. Maklashina E, Berthold DA, Cecchini G. Anaerobic expression of Escherichia coli succinate dehydrogenase: Functional replacement of fumarate reductase in the respiratory chain during anaerobic growth. J Bacteriol. 1998;180:5989-96.

118. Ruprecht J, Yankovskaya V, Maklashina E, Iwata S, Cecchini G. Structure of Escherichia coli succinate: quinone oxidoreductase with an occupied and empty quinone-binding site. J Biol Chem. 2009;284:29836-46.

119. Starbird CA, Tomasiak TM, Singh PK, Yankovskaya V, Maklashina E, Eisenbach $M$, et al. New crystal forms of the integral membrane Escherichia coli quinol:fumarate reductase suggest that ligands control domain movement. J Struct Biol. 2018:202:100-4.

120. Wilkinson WO, Walsh JP, Corless JM, Bell RM. Crystalline arrays of the Escherichia coli sn-glycerol-3-phosphate acyltransferase, an integral membrane protein. J Biol Chem. 1986;261:9951-8.

121. Wilkison WO, Bell RM, Taylor KA, Costello MJ. Structural characterization of ordered arrays of sn-glycerol-3-phosphate acyltransferase from Escherichia coli. J Bacteriol. 1992;174:6608-16. 
122. von Meyenburg K, Jogersen BB, van Deurs B. Physiological and morphological effects of overproduction of membrane-bound ATP synthase in Escherichia coli K-12. EMBO J. 1984;3:1791-7.

123. Arechaga I, Miroux B, Karrasch S, Huijbregts R, de Kruijff B, Runswick MJ, et al. Characterisation of new intracellular membranes in Escherichia coli accompanying large scale over-production of the $b$ subunit of $F 1 F$ o ATP synthase. FEBS Lett. 2000;482:215-9.

124. Revington M, Dunn SD, Shaw GS. Folding and stability of the $b$ subunit of the F 1 F 0 ATP synthase. J Biol Chem. 1999;274:31094-101.

125. Lefman J, Zhang P, Hirai T, Robert M, Juliani J, Bliss D, et al. Three-dimensional electron microscopic imaging of membrane invaginations in Escherichia coli overproducing the chemotaxis receptor Tsr. J Bacteriol. 2004;186:5052-61.

126. Grebe TW, Stock J. Bacterial chemotaxis: The five sensors of a bacterium. Curr Biol. 2004;8:R154-7

127. Kim S-H, Wang W, Kim KK. Dynamic and clustering model of bacterial chemotaxis receptors: Structural basis for signaling and high sensitivity. Proc Natl Acad Sci. 2002;99:11611-5.

128. Zhang P, Khursigara CM, Hartnell LM, Subramaniam S. Direct visualization of Escherichia coli chemotaxis receptor arrays using cryo-electron microscopy. Proc Natl Acad Sci U S A. 2007;104:3777-81.

129. Kärgel E, Menzel R, Honeck H, Vogel F, Böhmer A, Schunck W. Candida maltosa NADPH-cytochrome P450 Reductase: Cloning of a full-length CDNA, heterologous expression in Saccharomyces cerevisiae and function of the N-terminal region for membrane anchoring and proliferation of the endoplasmic reticulum. Yeast. 1996;12:333-48.

130. Becker F, Block-Alper L, Nakamura G, Harada J, Wittrup KD, Meyer DI. Expression of the $180-\mathrm{kD}$ ribosome receptor induces membrane proliferation and increased secretory activity in yeast. J Cell Biol. 1999;146:273-84.

131. Albertini M, Girzalsky W, Veenhuis M, Kunau WH. Pex12p of Saccharomyces cerevisiae is a component of a multi-protein complex essential for peroxisomal matrix protein import. Eur J Cell Biol. 2001:80:257-70.

132. Vergères G, Yen TSB, Aggeler J, Lausier J, Waskell L. A model system for studying membrane biogenesis Overexpression of cytochrome b5 in yeast results in marked proliferation of the intracellular membrane. J Cell Sci. 1993;106:249-59.

133. Rubino L, Di Franco A, Russo M. Expression of a plant virus nonstructural protein in Saccharomyces cerevisiae causes membrane proliferation and altered mitochondrial morphology. J Gen Virol. 2000;81:279-86

134. Zimmer T, Vogel F, Ohta A, Takagi M, Schunck W-H. Protein quality-A determinant of the intracellular fate of membrane-bound cytochromes P450 in Yeast. DNA Cell Biol. 1997:16:501-14.

135. Profant DA, Roberts CJ, Koning AJ, Wright RL. The role of the 3-hydroxy 3-methylglutaryl coenzyme A reductase cytosolic domain in Karmellae biogenesis. Mol Biol Cell. 1999;10:3409-23.

136. Snapp EL, Hegde RS, Francolini M, Lombardo F, Colombo S, Pedrazzini E, et al. Formation of stacked ER cisternae by low affinity protein interactions. J Cell Biol. 2003;163:257-69.

137. Van Den Brink-van Der Laan E, Boots JP, Spelbrink REJ, Kool GM, Breukink E, Killian JA, et al. Membrane Interaction of the glycosyltransferase MurG: a special role for cardiolipin. J Bacteriol. 2003;185:1-7.

138. Metzger IVLE, Raetz CRH. Purification and characterization of the lipid A disaccharide synthase ( $L p \times B)$ from Escherichia coli, a peripheral membrane protein. Biochemistry. 2009;48:11559-71.

139. Linna D, Aktas M, Unger A, Linke WA, Erdmann R, Narberhaus F. Membrane remodeling by a bacterial phospholipid-methylating enzyme. MBio. 2017:8:1-15

140. Eriksson HM, Wessman P, Ge C, Edwards K, Wieslander A.. Massive formation of intracellular membrane vesicles in Escherichia coli by a monotopic membrane-bound lipid glycosyltransferase. J Biol Chem. 2009;284:33904-14

141. Ge C, Gõmez-Llobregat J, Skwark MJ, Ruysschaert JM, Wieslander Å, Lindén M. Membrane remodeling capacity of a vesicle-inducing glycosyltransferase. FEBS J. 2014:281:3667-84.

142. Ariöz C, Götzke H, Lindholm L, Eriksson J, Edwards K, Daley DO, et al. Heterologous overexpression of a monotopic glucosyltransferase (MGS) induces fatty acid remodeling in Escherichia coli membranes. Biochim Biophys Acta - Biomembr. 2014;1838:1862-70.
143. Lee AG. How lipids affect the activities of integral membrane proteins. Biochim Biophys Acta - Biomembr. 2004;1666:62-87.

144. Oesterhelt D, Stoeckenius W. Rhodopsin-like Protein from the Purple Membrane of Halobacterium halobium. Nat New Biol. 1971;233:149-52.

145. Henderson R. The purple membrane from Halobacterium halobium. Annu Rev Biophys Bioeng. 1977;6:87-109.

146. Yokoyama Y, Yamada K, Higashi Y, Ozaki S, Wang H, Koito N, et al. Dependence of purple membrane bump curvature on $\mathrm{pH}$ and ionic strength analyzed using atomic force microscopy combined with solvent exchange. J Phys Chem B. 2014;118:9322-8.

147. Rhinow D, Hampp N. Curvature of purple membranes comprising permanently wedge-shaped bacteriorhodopsin molecules is regulated by lipid content. J Phys Chem B. 2010;114:549-56.

148. Boyd KJ, Alder NN, May ER. Buckling under pressure: curvature-based lipid segregation and stability modulation in cardiolipin-containing bilayers. Langmuir. 2017;33:6937-46.

149. Carranza G, Angius F, Ilioaia O, Solgadi A, Miroux B, Arechaga I. Cardiolipin plays an essential role in the formation of intracellular membranes in Escherichia coli. Biochim Biophys Acta - Biomembr. 2017;1859:1124-32

150. Lum PY, Wright R. Degradation of HMG-CoA reductase-induced membranes in the rission yeast, Schizosaccharomyces pombe. J Cell Biol. 1995;131:81-94

151. Miller DJ, Schwartz MD, Dye BT, Ahlquist P. Engineered retargeting of viral RNA replication complexes to an alternative intracellular membrane. J Virol. 2003;77:12193-202.

152. Ivankin A, Kuzmenko I, Gidalevitz D. Cholesterol mediates membrane curvature during fusion events. Phys Rev Lett. 2012;108:1-5.

153. Krishna A, Sengupta D. Interplay between membrane curvature and cholesterol: Role of palmitoylated caveolin-1. Biophys J Biophysical Society. 2019;116:69-78.

154. Bonazzi F, Weikl TR. Membrane morphologies induced by arc-shaped scaffolds are determined by arc angle and coverage. Biophys J 2019;116:1239-47.

155. Cronan JE Jr, Rock CO. Biosynthesis of Membrane Lipids. EcoSal Plus. 2008. https://doi.org/10.1128/ecosalplus.3.6.4.

156. Parsons JB, Rock CO. Bacterial lipids: Metabolism and membrane homeostasis. Prog Lipid Res. 2013;52:249-76.

157. Sohlenkamp C, Geiger O. Bacterial membrane lipids: Diversity in structures and pathways. FEMS Microbiol Rev. 2015;40:133-59.

158. Lin TY, Weibel DB. Organization and function of anionic phospholipids in bacteria. Appl Microbiol Biotechnol. 2016;100:4255-67.

159. Cronan JE Jr, Bell RM. Mutants of Escherichia coli defective in membrane phospholipid synthesis. J Bacteriol. 1974;118:598-605.

160. Bell RM, Cronan JE Jr. Mutants of Escherichia coli defective in membrane phospholipid synthesis. Phenotypic suppression of sn-glycerol-3-phosphate acyltransferase Km mutants by loss of feedback inhibition of the biosynthetic sn-glycerol-3-phosphate dehydrogenase. J Biol Chem. 1975:250:7153-8.

161. Mclntyre TM, Chamberlain BK, Wester RE, Bell RM. Mutants of Escherichia phospholipid synthesis coli defective in membrane by loss of feedback. J Biol Chem. 1977;252:4487-93.

162. Seyfzadeh M, Keener J, Nomura M. spoT-dependent accumulation of guanosine tetraphosphate in response to fatty acid starvation in Escherichia coli. Proc Natl Acad Sci USA 2006;90:11004-8.

163. Gopalkrishnan S, Nicoloff H, Ades SE. Co-ordinated regulation of the extracytoplasmic stress factor, sigmaE, with other Escherichia coli sigma factors by (p)ppGpp and DksA may be achieved by specific regulation of individual holoenzymes. Mol Microbiol. 2014;93:479-93.

164. Bury-Moné S, Nomane Y, Reymond N, Barbet R, Jacquet E, Imbeaud S, et al. Global analysis of extracytoplasmic stress signaling in Escherichia coli. PLoS Genet. 2009;5:213

165. Louie K, Chen YC, Dowhan W. Substrate-induced membrane association of phosphatidylserine synthase from Escherichia coli. J Bacteriol. 1986;165:805-12

166. Satomi N, Kumar Saha S, Matsumoto K, Shibuya I, Matsuzaki H. A regulatory mechanism for the balanced synthesis of membrane phospholipid species in Escherichia coli. Biosci Biotechnol Biochem. 1996;60:111-6.

167. Rowlett VW, Mallampalli VKPS, Karlstaedt A, Dowhan W, Taegtmeyer $\mathrm{H}$, Margolin W, et al. The impact of membrane phospholipid alterations in Escherichia coli on cellular function. J Bacteriol. 2017:199:1-22. 
168. Price NL, Raivio TL. Characterization of the Cpx Regulon in Escherichia coli Strain MC4100. J Bacteriol. 2009;191:1798-815.

169. Raivio TL, Leblanc SKD, Price NL. The Escherichia coli Cpx envelope stress response regulates genes of diverse function that impact antibiotic resistance and membrane integrity. J Bacteriol. 2013;195:2755-67.

170. Raivio TL. Everything old is new again: An update on current research on the Cpx envelope stress response. Biochim Biophys Acta - Mol Cell Res. 2014;1843:1529-41.

171. Stenberg-Bruzell F, Daley DO, Wieslander Å, Ariöz C, Keller R, Vikström $D$, et al. The Escherichia coli envelope stress sensor CpxA responds to changes in lipid bilayer properties. Biochemistry. 2015;54:3670-6.

172. Arias-Cartin R, Grimaldi S, Arnoux P, Guigliarelli B, Magalon A. Cardiolipin binding in bacterial respiratory complexes: Structural and functional implications. Biochim Biophys Acta - Bioenerg. 2012;1817:1937-49.

173. Yankovskaya V, Horsefield R, Tornroth S, Luna-Chavez C, Miyoshi H, Leger $C$, et al. Architecture of succinate dehydrogenase and reactive. Science. 2003;299:700-4.

174. Laage S, Tao Y, McDermott AE. Cardiolipin interaction with subunit $\mathrm{c}$ of ATP synthase: Solid-state NMR characterization. Biochim Biophys Acta Biomembr. 2015:1848:260-5.

175. Mehdipour AR, Hummer G. Cardiolipin puts the seal on ATP synthase. Proc Natl Acad Sci USA 2016;113:8568-70.

176. Duncan AL, Ruprecht JJ, Kunji ERS, Robinson AJ. Cardiolipin dynamics and binding to conserved residues in the mitochondrial ADP/ATP carrier. Biochim Biophys Acta - Biomembr. 2018;1860:1035-45

177. von Heijne G. Control of topology and mode of assembly of a polytopic membrane protein by positively charged residues. Nature. 1989;399:655-6.

178. Elazar A, Weinstein JJ, Prilusky J, Fleishman SJ. Interplay between hydrophobicity and the positive-inside rule in determining membraneprotein topology. Proc Natl Acad Sci. 2016;113:10340-5.

179. Baker JA, Wong WC, Eisenhaber B, Warwicker J, Eisenhaber F. Charged residues next to transmembrane regions revisited: "Positive-inside rule" is complemented by the "negative inside depletion/outside enrichment rule.". BMC Biol. 2017;15:1-29.

180. Gubellini F, Verdon G, Karpowich NK, Luff JD, Boël G, Gauthier N, et al. Physiological response to membrane protein overexpression in E. coli. Mol Cell Proteomics. 2011:10:M111.007930

181. Ha S, Walker D, Shi Y, Walker S. The $1.9 \AA$ A crystal structure of Escherichia coli MurG, a membrane-associated glycosyltransferase involved in peptidoglycan biosynthesis. Protein Sci. 2009;9:1045-52.

182. Mi W, LiY, Yoon SH, Ernst RK, Walz T, Liao M. Structural basis of MsbAmediated lipopolysaccharide transport. Nature. 2017;549:233-7.

183. Oh A, Alexander MK, Ho H, Garcia NK, Verma V, Beresini MH, et al. Structural basis for dual-mode inhibition of the $A B C$ transporter MsbA. Nature. 2018:557:196-201.

184. Huang Y, Lemieux MJ, Song J, Auer M, Wang D-N. Structure and mechanism of the glycerol-3-phosphate transporter from Escherichia coli. Science. 2003:301:616-20.

185. Sezgin E, Levental I, Mayor S, Eggeling C. The mystery of membrane organization: composition, regulation and roles of lipid rafts. Nat Rev Mol Cell Biol 2017;18:361-74.

186. Bramkamp M, Lopez D. Exploring the existence of lipid rafts in bacteria. Microbiol Mol Biol Rev. 2015;79:81-100.

187. Renner LD, Weibel DB. Cardiolipin microdomains localize to negatively curved regions of Escherichia coli membranes. Proc Natl Acad Sci. 2011:108:6264-9.

188. Boyd KJ, Alder NN, May ER. Molecular dynamics analysis of cardiolipin and monolysocardiolipin on bilayer properties. Biophys J. 2018:114:2116-27.

189. Beltrán-Heredia E, Tsai F-C, Salinas-Almaguer S, Cao FJ, Bassereau P, Monroy F. Membrane curvature induces cardiolipin sorting. Commun Biol. 2019;2:1-7.

190. van Weeghel RP, Keck W, Robillard GT. Regulated high-level expression of the mannitol permease of the phosphoenolpyruvate-dependent sugar phosphotransferase system in Escherichia coli. Proc Natl Acad Sci USA 1990;87:2613-7.

191. Nieboer M, Vis AJ, Witholt B. Overproduction of a foreign membrane protein in Escherichia coli stimulates and depends on phospholipid synthesis. Eur J Biochem. 1996;241:691-6.
192. Wilkison WO, Bell RM. sn-Glycerol-3-phosphate acyltransferase tubule formation is dependent upon heat shock proteins (htpR). J Biol Chem. 1988:263:14505-10.

193. Ariöz C, Ye W, Bakali A, Ge C, Liebau J, Götzke H, et al. Anionic lipid binding to the foreign protein MGS Provides a tight coupling between phospholipid synthesis and protein overexpression in escherichia coli. Biochemistry. 2013;52:5533-44.

194. Cox JS, Chapman RE, Walter P. The unfolded protein response coordinates the production of endoplasmic reticulum protein and endoplasmic reticulum membrane. Mol Biol Cell. 1997;8:1805-14.

195. Volmer R, Ron D. Lipid-dependent regulation of the unfolded protein response. Curr Opin Cell Biol. 2015;33:67-73.

196. Ho N, Xu C, Thibault G. From the unfolded protein response to metabolic diseases - lipids under the spotlight. J Cell Sci. 2018;131:jcs199307.

197. Fun XH, Thibault G. Lipid bilayer stress and proteotoxic stress-induced unfolded protein response deploy divergent transcriptional and nontranscriptional programmes. Biochim Biophys Acta - Mol Cell Biol Lipids. 2019. https://doi.org/10.1016/j.bbalip.2019.04.009.

198. Travers KJ, Patil CK, Wodicka L, Lockhart DJ, Weissman JS, Walter P. Functional and genomic analyses reveal an essential coordination between the Unfolded Protein Response and ER-associated degradation. Cell. 2000;101:249-58.

199. Menzel R, Vogel F, Kärgel E, SchunckWH. Inducible membranes in yeast: Relation to the unfolded-protein-response pathway. Yeast. 1997;13:1211-29.

200. Stroobants AK, Hettema EH, Van Den Berg M, Tabak HF. Enlargement of the endoplasmic reticulum membrane in Saccharomyces cerevisiae is not necessarily linked to the unfolded protein response via Ire1 p. FEBS Lett. 1999:453:210-4.

201. Guerfal M, Ryckaert S, Jacobs PP, Ameloot P, Van Craenenbroeck K Derycke R, et al. The HAC1 gene from Pichia pastoris: Characterization and effect of its overexpression on the production of secreted, surface displayed and membrane proteins. Microb Cell Fact. 2010;9:1-12.

202. Vogl T, Thallinger GG, Zellnig G, Drew D, Cregg JM, Glieder A, et al. Towards improved membrane protein production in Pichia pastoris: General and specific transcriptional response to membrane protein overexpression. N Biotechnol. 2014:31:538-52.

203. Block-Alper L, Webster P, Zhou X, Supekova L, Wong WH, G.Schultz $P$, et al. IN02, a positive regulator of lipid biosynthesis, is essential for the formation of inducible membranes in yeast. Mol Biol Cell. 2002;13:40-51.

204. Henry SA, Gaspar ML, Jesch SA. The response to inositol: Regulation of glycerolipid metabolism and stress response signaling in yeast. Chem Phys Lipids. 2014;180:23-43.

205. Carman GM, Henry SA. Phosphatidic acid plays a central role in the transcriptional regulation of glycerophospholipid synthesis in Saccharomyces cerevisiae. J Biol Chem. 2007;282:37293-7.

206. Loewen CJR, Gazpar ML, Jesch SA, Delon C, Ktistakis NT, Henry SA, et al. Phospholipid metabolism regulated by a transcription factor sensing phosphatidic acid. Science. 2004:304:1644-7.

207. Young BP, Shin JJH, Orij R, Chao JT, Li SC, Guan XL, et al. Phosphatidic acid is a pH biosensor. Science. 2010;329:1085-8.

208. Carman GM, Han G-S. Regulation of phospholipid synthesis in the yeast Saccharomyces cerevisiae. Annu Rev Biochem. 2011;80:859-83.

209. Nishikawa S, Hirata A, Nakano A. Inhibition of endoplasmic reticulum (ER)-to-Golgi transport induces relocalization of binding protein (BiP) within the ER to form the BiP bodies. Mol Biol Cell. 1994;5:1129-43.

210. Elgersma Y, Kwast L, Van Den Berg M, Snyder WB, Distel B, Subramani S, et al. Overexpression of Pex15p, a phosphorylated peroxisomal integral membrane protein required for peroxisome assembly in $\mathrm{S}$. cerevisiae, causes proliferation of the endoplasmic reticulum membrane. EMBO J. 1997;16:7326-41.

211. Santos-Rosa H, Leung J, Grimsey N, Peak-Chew S, Siniossoglou S. The yeast lipin Smp2 couples phospholipid biosynthesis to nuclear membrane growth. EMBO J. 2005:24:1931-41.

212. Han GS, Siniossoglou S, Carman GM. The cellular functions of the yeast lipin homolog Pah1p are dependent on its phosphatidate phosphatase activity. J Biol Chem. 2007;282:37026-35. 
213. Han GS, O'Hara L, Carman GM, Siniossoglou S. An unconventional diacylglycerol kinase that regulates phospholipid synthesis and nuclear membrane growth. J Biol Chem. 2008;283:20433-42.

214. Kameoka S, Adachi Y, Okamoto K, lijima M, Sesaki H. Phosphatidic acid and cardiolipin coordinate mitochondrial dynamics. Trends Cell Biol. 2018;8:67-76

215. De Kroon AIPM, Rijken PJ, De Smet $\mathrm{CH}$. Checks and balances in membrane phospholipid class and acyl chain homeostasis, the yeast perspective. Prog Lipid Res. 2013;52:374-94.

216. Kooijman EE, Burger KNJ. Biophysics and function of phosphatidic acid: A molecular perspective. Biochim Biophys Acta - Mol Cell Biol Lipids. 2009;1791:881-8.

217. Sathappa M, Alder NN. The ionization properties of cardiolipin and its variants in model bilayers. Biochim Biophys Acta - Biomembr. 2016;1858:1362-72.

218. Khalifat N, Fournier JB, Angelova MI, Puff N. Lipid packing variations induced by $\mathrm{pH}$ in cardiolipin-containing bilayers: The driving force for the cristae-like shape instability. Biochim Biophys Acta - Biomembr. 2011;1808:2724-33.

219. Kensbock $\mathrm{R}$, Ahrens $\mathrm{H}$, Helm CA. Interactions of monovalent and divalent cations with cardiolipin monolayers. Langmuir. 2019;35:3624-33.

220. Ohkuma M, Park SM, Zimmer T, Menzel R, Vogel F, Schunck W-H, et al. Proliferation of intracellular membrane structures upon homologous overproduction of cytochrome P-450 in Candida maltosa. Biochim Biophys Acta. 1995;1236:163-9.

221. Menzel R, Kärgel E, Vogel F, Böttcher C, SchunckWH. Topogenesis of a microsomal cytochrome $\mathrm{P} 450$ and induction of endoplasmic reticulum membrane proliferation in Saccharomyces cerevisiae. Arch Biochem Biophys. 1996;330:97-109.
222. Sandig G, Kärgel E, Menzel R, Vogel F, Zimmer T, Schunck W-H. Regulation of endoplasmatic reticulum biogenesis in response to cytochrome P450 overproduction. Drug Metab Rev. 1999;31:393-410.

223. Supply P, Wach A, Thines-Sempoux D, Goffeau A. Proliferation of intracellular structures upon overexpression of the PMA2 ATPase in Saccharomyces cerevisiae. J Biol Chem. 1993;268:19744-52.

224. Wanker EE, Sun Y, Savitz AJ, Meyer DI. Functional characterization of the 180-kD ribosome receptor in vivo. J Cell Biol. 1995;130:29-39.

225. Grünewald S, Haase W, Molsberger E, Michel H, Reiländer H. Produc tion of the human D2S receptor in the methylotrophic yeast P. pastoris. Recept Channels. 2004;10:37-50.

226. Licata L, Haase W, Eckhardt-Strelau L, Parcej DN. Over-expression of a mammalian small conductance calcium-activated $K+$ channel in Pichia pastoris: effects of trafficking signals and subunit fusions. Protein Expr Purif. 2006;47:171-8.

227. Song X, Shukla S, Oh S, Kim Y, Kim M. Development of fluorescencebased liposome immunoassay for detection of cronobacter muytjensii in pure culture. Curr Microbiol. 2015;70:246-52.

228. Smith S, Blobel G. Colocalization of vertebrate lamin B and lamin B receptor (LBR) in yeast Saccharomyces cereviiae. Proc Natl Acad Sci USA 1994;91:10124-8.

\section{Publisher's Note}

Springer Nature remains neutral with regard to jurisdictional claims in published maps and institutional affiliations.
Ready to submit your research? Choose BMC and benefit from:

- fast, convenient online submission

- thorough peer review by experienced researchers in your field

- rapid publication on acceptance

- support for research data, including large and complex data types

- gold Open Access which fosters wider collaboration and increased citations

- maximum visibility for your research: over $100 \mathrm{M}$ website views per year

At BMC, research is always in progress.

Learn more biomedcentral.com/submissions 